\title{
Expectations Do Not Alter Early Sensory Processing during Perceptual Decision-Making
}

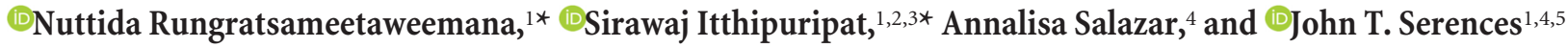 \\ ${ }^{1}$ Neurosciences Graduate Program, University of California, San Diego, La Jolla, California 92093-0109, ${ }^{2}$ Learning Institute, King Mongkut's University of \\ Technology Thonburi, Bangkok, Thailand 10140, ${ }^{3}$ Department of Psychology, Vanderbilt University, Nashville, Tennessee 37235, ${ }^{4}$ Department of \\ Psychology, University of California, San Diego, La Jolla, California 92093-0109, and ${ }^{5}$ Kavli Institute for Brain and Mind, University of California, San Diego, \\ La Jolla, California 92093-0109
}

Two factors play important roles in shaping perception: the allocation of selective attention to behaviorally relevant sensory features, and prior expectations about regularities in the environment. Signal detection theory proposes distinct roles of attention and expectation on decision-making such that attention modulates early sensory processing, whereas expectation influences the selection and execution of motor responses. Challenging this classic framework, recent studies suggest that expectations about sensory regularities enhance the encoding and accumulation of sensory evidence during decision-making. However, it is possible, that these findings reflect well documented attentional modulations in visual cortex. Here, we tested this framework in a group of male and female human participants by examining how expectations about stimulus features (orientation and color) and expectations about motor responses impacted electroencephalography (EEG) markers of early sensory processing and the accumulation of sensory evidence during decision-making (the early visual negative potential and the centro-parietal positive potential, respectively). We first demonstrate that these markers are sensitive to changes in the amount of sensory evidence in the display. Then we show, counter to recent findings, that neither marker is modulated by either feature or motor expectations, despite a robust effect of expectations on behavior. Instead, violating expectations about likely sensory features and motor responses impacts posterior alpha and frontal theta oscillations, signals thought to index overall processing time and cognitive conflict. These findings are inconsistent with recent theoretical accounts and suggest instead that expectations primarily influence decisions by modulating post-perceptual stages of information processing.

Key words: cognitive control; decision-making; electroencephalography (EEG); expectation; sensory modulation

Significance Statement

Expectations about likely features or motor responses play an important role in shaping behavior. Classic theoretical frameworks posit that expectations modulate decision-making by biasing late stages of decision-making including the selection and execution of motor responses. In contrast, recent accounts suggest that expectations also modulate decisions by improving the quality of early sensory processing. However, these effects could instead reflect the influence of selective attention. Here we examine the effect of expectations about sensory features and motor responses on a set of electroencephalography (EEG) markers that index early sensory processing and later post-perceptual processing. Counter to recent empirical results, expectations have little effect on early sensory processing but instead modulate EEG markers of time-on-task and cognitive conflict.

\section{Introduction}

Selectively attending to relevant sensory inputs (i.e., selective attention) leads to faster and more accurate decisions. In addition,

\footnotetext{
Received Dec. 26, 2017; revised April 27, 2018; accepted May 4, 2018.

Author contributions: S.I. and J.T.S. designed research; S.I. and A.S. performed research; N.R., A.S., and J.T.S. contributed unpublished reagents/analytic tools; N.R., S.I., and A.S. analyzed data; N.R. and J.T.S. wrote the paper.

This work was supported by NEI R01EY025872 and James S. McDonnell Foundation awards to J.T.S. and by HHMI International Predoctoral Fellowship and a Royal Thai Scholarship from the Ministry of Science and Technology in Thailand to S.I. We thank Stephanie Nelli, Vy Vo, and Rosanne Rademaker for useful discussions.

The authors declare no competing financial interests.

*N.R. and S.I. contributed equally to this work.
}

expectations based on learned statistical regularities in incoming sensory signals or motor responses can also facilitate decisionmaking, even if the expectations concern features or responses that are irrelevant with respect to current behavioral goals (Summerfield and de Lange, 2014). Selective attention is thought to improve information processing primarily by modulating the re-

Correspondence should be addressed to either Nuttida Rungratsameetaweemana or John T. Serences, Neurosciences Graduate Program, University of California, San Diego, 9500 Gilman Drive, La Jolla, CA 92093. E-mail: nrungrat@ucsd.edu or jserences@ucsd.edu.

DOI:10.1523/JNEUROSCI.3638-17.2018

Copyright $\odot 2018$ the authors $\quad 0270-6474 / 18 / 385632-17 \$ 15.00 / 0$ 
sponse properties of neurons in early sensory areas (Desimone and Duncan, 1995; Reynolds and Chelazzi, 2004; Maunsell and Treue, 2006; Serences and Kastner, 2014; Itthipuripat and Serences, 2016). In contrast, classic theoretical frameworks such as signal detection theory (SDT) hold that expectations do not influence early sensory responses, but instead bias later cognitive operations related to response selection and execution (Wald and Wolfowitz, 1949; Green and Swets, 1966; Wolfe, 1998; Berti and Schröger, 2004; Alvarez et al., 2007). Consistent with this idea, a recent behavioral study has shown that stimulus expectations modulated decision criteria without affecting the quality of early sensory signals (Bang and Rahnev, 2017).

Challenging this traditional SDT-based account, recent work suggests that expectations can improve the efficiency of early sensory processing, even when expectations are independent of behavioral goals (Kok et al., 2012a; Wyart et al., 2012b; Summerfield and de Lange, 2014; Cheadle et al., 2015). On this account, expectations increase the precision of information processing by sharpening population-level response profiles in early visual cortex (Lee and Mumford, 2003; Spratling, 2008; Kok et al., 2012a; Jiang et al., 2013). Accordingly, it has been proposed that expectation-related modulations in early visual cortex should directly increase the efficiency of early sensory processing during perceptual decision-making (Summerfield and de Lange, 2014).

However, previous studies examining the impact of expectations on early sensory processing used explicit cues to indicate which stimulus feature had the highest probability of being a target (Wyart et al., 2012b; Cheadle et al., 2015; Kok et al., 2012a, 2016). Importantly, these explicit cues are similar to cues used in other studies to direct the allocation of visual attention to behaviorally relevant spatial locations or features (Motter, 1993; McAdams and Maunsell, 1999; Martínez-Trujillo and Treue, 2004; Scolari et al., 2012, 2014; Itthipuripat et al., 2014a,b; Störmer and Alvarez, 2014; Ester et al., 2016). Therefore, reported expectation effects may actually reflect the operation of the same mechanisms that have been well documented in the selective attention literature (Motter, 1993; McAdams and Maunsell, 1999; MartínezTrujillo and Treue, 2004).

Here we test the classic SDT account and this new sensory enhancement account to better understand how expectations impact early sensory processing (Kok et al., 2012a; Summerfield and de Lange, 2014). We manipulated expectations about two different low-level sensory features (color and orientation). We also included two additional conditions: (1) a manipulation of the amount of sensory evidence available in each stimulus display to validate electroencephalography (EEG) markers of early sensory processing, and (2) an independent manipulation of motor expectation as a point of comparison with feature expectation. Finally, expectations were established based on implicitly learned regularities and we independently manipulated expectations about each component of the task so that statistical regularities in one feature dimension (e.g., color) would not provide information about the relevance of a target defined in the other feature dimension (i.e., orientation). As a result of these design features, the task dissociated manipulations of expectations from the effects of using an explicit cue to provide information about the behaviorally relevant target feature.

\section{Materials and Methods}

Participants. Twenty healthy volunteers (8 males; all participants righthanded; mean age $=21.8, \mathrm{SD}=3.3$ ) participated in the experiment. All were neurologically intact and had normal or corrected-to-normal color vision. Participants gave written informed consent and were compen- sated $\$ 15 / \mathrm{h}$ for participation. Ethical approval was granted by the Institutional Review Board at the University of California, San Diego. Each participant underwent two EEG recording sessions (sessions were $\sim 2 \mathrm{~h}$ each, with 1920 trials collected in total). Three participants were excluded from data analysis for having $<70 \%$ artifact-free trials in any of the conditions of interest (due to excessive muscle movement and eye movements), leaving 17 participants in the final analyses (see EEG recording and analysis section for details).

Stimuli. Visual stimuli consisted of 200 blue bars and 200 red bars (length $=1.39^{\circ}$, width $=0.18^{\circ}$ ) displayed in an annulus (outer diameter, $22^{\circ}$; inner diameter, $2.4^{\circ}$ ) surrounding a black fixation point on a dark gray background of $42.68 \pm 2.20 \mathrm{~cd} / \mathrm{m}^{2}$. Blue and red bars within the annulus flickered at $33.33 \mathrm{~Hz}(33.33 \%$ on-off duty cycle) and $50 \mathrm{~Hz}$, respectively ( $50 \%$ on-off duty cycle; or vice versa) for the duration of the trial, and the location of each bar was randomly reassigned within the aperture at the beginning of each flicker cycle. The combination of color and flicker rate was counterbalanced across trials. At the beginning of each trial, each bar was first randomly assigned to one of eight possible orientations $\left(0-157.5^{\circ}\right.$ in $22.5^{\circ}$ increments). For a target display, $68.5 \%$ of either red or blue lines were assigned a common orientation of either $0^{\circ}$ or $90^{\circ}$, whereas all other bars were assigned one of seven remaining orientations. Participants were instructed to report the predominant orientation of these iso-oriented bars via a USB compatible keypad.

Stimuli were presented on a PC running Windows XP using MATLAB (MathWorks) and the Psychophysics Toolbox v3.0.8 (Pelli, 1985; Brainard, 1997). Participants were seated in a sound-attenuated and electromagnetically shielded room (ETS Lindgren) $60 \mathrm{~cm}$ from the CRT monitor running at $100 \mathrm{~Hz}$ with a gray background of $42.68 \pm 2.20 \mathrm{~cd} / \mathrm{m}^{2}$.

Procedures. Participants performed two sessions of an orientation discrimination task in which feature expectation (i.e., color expectation and orientation expectation) and motor expectation were independently manipulated on a block-by-block basis (Fig. 1). As described, targets were red or blue bars coherently oriented at $0^{\circ}$ (horizontal) or $90^{\circ}$ (vertical), hence there were four possible target types: red horizontal, red vertical, blue horizontal, and blue vertical targets. Each response button was associated with a specific conjunction of color and orientation. Half of the participants were instructed to map the left button to red horizontal and blue vertical targets and the right button to blue horizontal and red vertical targets. The other half of the participants were given the opposite response-mapping instructions. This stimulus-response mapping was adopted so that we could completely dissociate expectation about sensory features and expectation about motor responses.

To familiarize participants with the task and the response mapping, participants performed a behavioral training session before the first EEG session. During this training session, participants had to complete 10 full blocks of the experimental task, with each block containing four trials from each of the four expectation types (neutral, color expectation, orientation expectation, motor expectation; see the next paragraph). The training session was terminated once participants achieved perfect performance on all blocks, and each block was repeated until participants reached $100 \%$ accuracy.

After training, each EEG session was comprised of 16 experimental blocks with 60 trials in each block. This yielded four blocks of trials for each of the four expectation types: neutral, color expectation, orientation expectation, or motor expectation (Fig. 1). In the neutral blocks, all four target types were presented equally often. In the remaining blocks, feature and motor expectations were manipulated orthogonally, such that feature expectation and motor expectation were never manipulated at the same time within the same block. Feature expectation was manipulated by presenting either one color more frequently (i.e., color expectation) or one orientation more frequently (i.e., orientation expectation) than the other value in that feature dimension. For example, on one type of color expectation block, the target would be rendered in red on $70 \%$ of the trials and in blue on $30 \%$ of the trials. Importantly, on these color expectation blocks, target identity was perfectly balanced such that $50 \%$ of the target was horizontal and $50 \%$ was vertical. In contrast, on an orientation expectation block, $70 \%$ of the targets would be horizontal and $30 \%$ of the targets would be vertical, with an equal number of targets composed of blue and red lines. Finally, on a motor expectation block, 
A
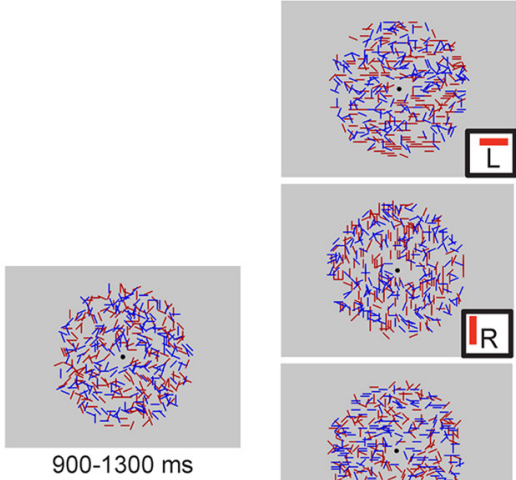

Target-Response No Mapping Expectation

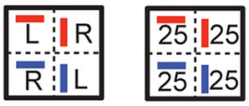

Color Expectation

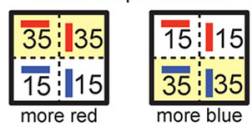

Orientation Expectation

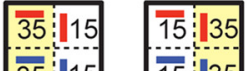

\begin{tabular}{l:l:l:l}
\hline 35 & 15 \\
\hline
\end{tabular}

Motor Expectation

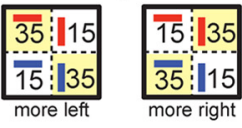

Time

B

Orientation Expectation

Color Expectation

Motor Expectation
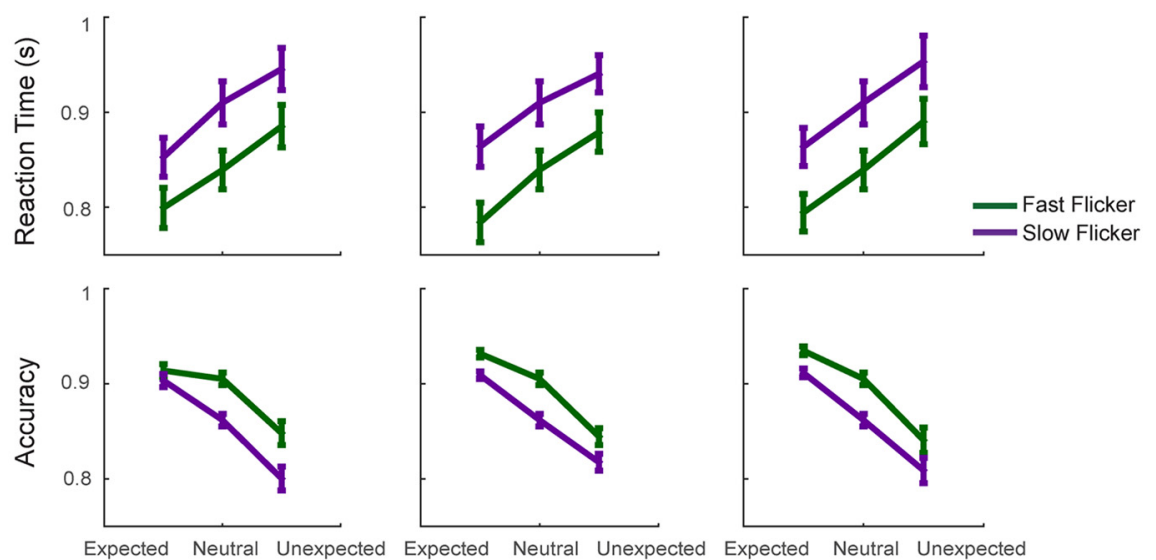

C

Orientation Expectation

Color Expectation
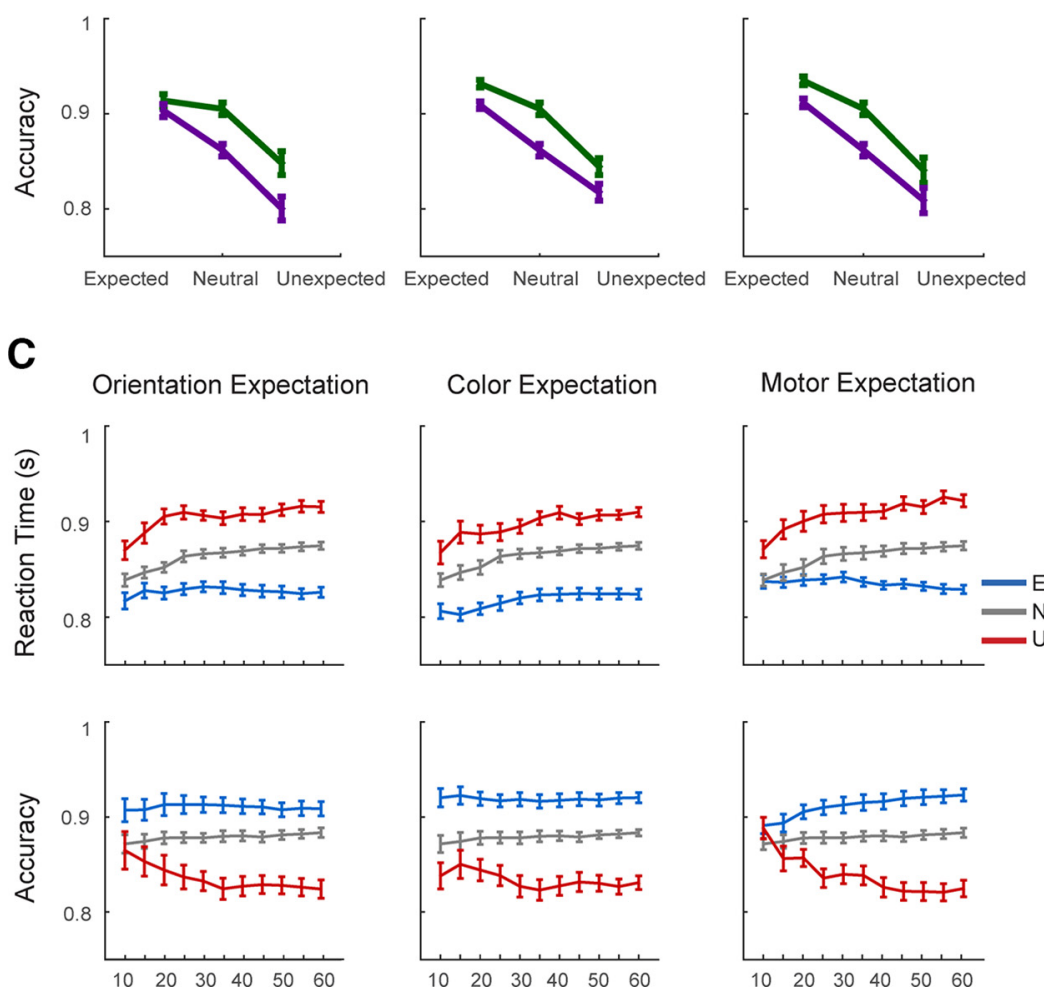
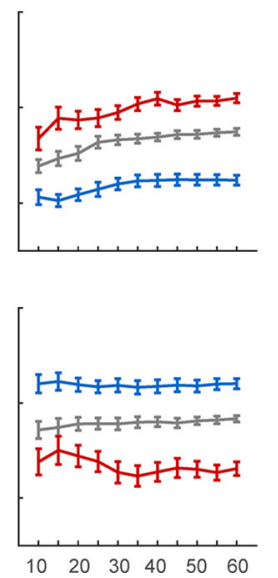
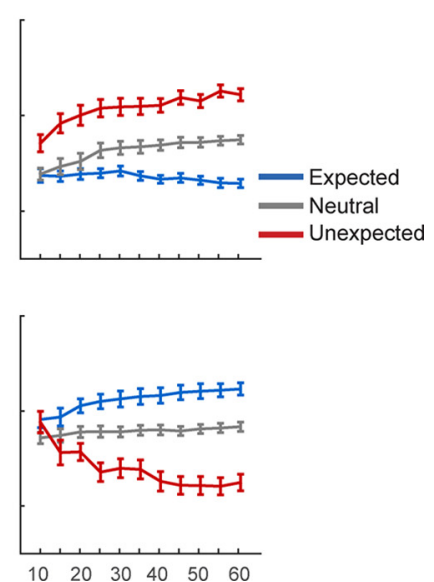

Motor Expectation

Figure 1. Orientation discrimination task and behavioral results. $\boldsymbol{A}$, Task schematics. Targets were either coherently oriented red or blue bars at $0^{\circ}$ (horizontal) or $90^{\circ}$ (vertical), and participants indicated the target by pressing the left (L) or right key (R). Each response button was associated with a specific conjunction of color and orientation such that half of the participants were instructed to map the left button to red horizontal and blue vertical targets and the right button to blue horizontal and red vertical targets. There were four expectation types to the task: neutral (no expectation), color expectation, orientation expectation, and

targets associated with the left button (e.g., red horizontal and blue vertical) were presented on $70 \%$ of the trials whereas the targets mapped to the right button (e.g., blue horizontal and red vertical) were presented on $30 \%$ of the trials. This experimental design thus enabled us to independently manipulate expectation about sensory features (i.e., target color and orientation) and expectation about motor responses. In addition, we could also control expectation within the "feature" domain by separately manipulating expectation about color and orientation of the target stimulus, as both features provided equal amount of information toward decision choices (left/right button press) on each trial. Together, this study design allowed us to examine the effects of feature expectation on information processing during decisionmaking in the absence of motor expectation and response bias.

Every block started with four practice trials that corresponded to each target type (red horizontal/red vertical/blue horizontal/blue vertical) to ensure that participants understood the assigned stimulus-response mapping. Participants had to provide correct responses for all four practice trials before the main task would proceed; otherwise the practice trials would repeat until participants met criterion performance. In the main task, each trial began with a pre-target display consisting of colored bars flickering at 33.33 and $50 \mathrm{~Hz}$ that lasted for 91-127 ms. During this pre-target interval, the

$\leftarrow$

motor expectation. Expectation types were manipulated on a block-by-block basis. Each target composed of two features: color and orientation, and the expectation status of the target was manipulated in the three expectation conditions by presenting one type of target more frequently than the other target type within the same target feature. That is, for a given block (e.g., color expectation block), one target type (e.g., red target) was expected, whereas the other target type (i.e., blue target) was unexpected. The other target feature (i.e., orientation) was orthogonal to this expectation manipulation, and it was equally likely that the target would be vertical or horizontal. Note that the ratio of expected-unexpected trials within each block is $70: 30$, such that in a color expectation block where red target is expected, the probabilities of red horizontal target, red vertical target, blue horizontal target, and blue vertical target are $35,35,15$, and $15 \%$ respectively. In the neutral expectation block, the probabilities of each of the four possible targets were $25 \%$ accordingly. B, Behavioral results. Accuracy was higher on the expected trials than on the unexpected trials in all three expectation types (orientation/ color/motor expectation). Accuracy was also higher on trials where stimuli were presented at a fast compared with a slow flicker rate. RTs for correct responses were also shorter for fast flicker-rated stimuli than for slow flicker-rated stimuli. C, Performance as a function of the number of cumulative trials in each block (i.e., trial 1-10, 1-15, 1-20, etc. within each block of 60 trials). Data were collapsed across fast and slow flicker rate trials to examine the temporal dynamics of the expectation effects on RTs and accuracy. Across the three expectation types, the effects of expectation on behavior are clearly observed after 20 cumulative trials. Thus, in later EEG analyses where a null effect of expectation is observed, we ran additional analyses after discarding the first 20 trials. 
orientation of each bar was pseudorandomly selected from a uniform distribution such that no coherent global orientation signal was present. Following the pre-target interval, the orientation target was presented for $850 \mathrm{~ms}$, followed by a $600 \mathrm{~ms}$ post-target display in which the orientation of all bars was again pseudorandomly drawn from a uniform distribution. The post-target display was followed by a feedback display which indicated whether the response on that trial was "too early" (made $<85$ ms after target onset), "correct", "incorrect", or "too slow" (made after trial offset). The feedback display was presented for $300 \mathrm{~ms}$ and immediately followed by an 800-1200 ms blank intertrial interval.

Behavioral analysis. We used a three-way repeated-measures ANOVA with factors for the expectation type (3 levels: color expectation, orientation expectation, and motor expectation), flicker rate ( 2 levels: fast and slow), and the status of the target (3 levels: expected, neutral, and unexpected) to test the main effects and interactions on the accuracy and reaction times associated with correct trials.

EEG recording and analysis. EEG data were recorded using a $64+8$ channel BioSemi ActiveTwo system at a sampling rate of $512 \mathrm{~Hz}$. Two reference electrodes were placed at the mastoids. We monitored vertical eye movements and blinks via two pairs of electrodes placed above and below the eyes. Horizontal eye movements were monitored via another pair of electrodes placed near the outer canthi of the eyes. The EEG data were referenced online to the BioSemi CMS-DRL reference, and all offsets from the reference were maintained $<20 \mu \mathrm{V}$. The data were preprocessed with a combination of EEGlab 11.03.1b (Delorme and Makeig, 2004) and custom MATLAB scripts.

After data collection, we re-referenced the continuous EEG data offline to the mean of the left and right mastoid electrodes and applied 0.25 $\mathrm{Hz}$ high-pass and $58 \mathrm{~Hz}$ low-pass Butterworth filters (third order). An additional $10 \mathrm{~Hz}$ low-pass filter was applied before plotting the data, but all reported statistics were performed on the $58 \mathrm{~Hz}$ low-pass filtered data (Luck, 2005; for similar methods, see Hickey et al., 2010; Itthipuripat and Serences, 2016). The data were then segmented into epochs extending from $1500 \mathrm{~ms}$ before to $4000 \mathrm{~ms}$ after the trial onset. Prominent eyeblink artifacts were first rejected by independent component analysis (Makeig et al., 1996). We then visualized data from each trial and discarded epochs contaminated by residual eye blinks and vertical eye movements ( $> \pm 80-150 \mu \mathrm{V}$ deviation from 0 , with thresholds chosen for each subject), horizontal eye movements ( $> \pm 75-100 \mu \mathrm{V}$ deviation from 0 ), excessive muscle activity, or drifts. This procedure resulted in the rejection of $12.25 \%$ of trials on average ( $\pm 1.07 \%$ SEM across subjects; ranged from 3.9 to $21.8 \%$ of trials). Data from three participants were excluded from further analysis due to the rejection rate of $>30 \%$ of trials $(31.35$, 60 , and $89 \%$, respectively).

Next, we sorted artifact-free EEG epochs into different experimental conditions based on expectation type (color expectation, orientation expectation, and motor expectation), the status of each target in the context of a given block (expected, neutral, or unexpected), and on the flicker rate of the target (fast or slow). To compute event-related potentials (ERPs), the EEG data from each experimental condition were first baseline-corrected from 200 to $0 \mathrm{~ms}$ before the onset of a target or a response. ERPs were then computed by averaging target-locked and response-locked EEG data for each experimental condition. In addition, the EEG data for individual subjects were also wavelet-filtered using a Gaussian filter with a 0.2 factional bandwidth centered on eight frequencies in $1 \mathrm{~Hz}$ incremental steps from 4 to $12 \mathrm{~Hz}$, yielding analytic amplitude estimates for oscillatory EEG components in the theta $(4-8 \mathrm{~Hz})$ and alpha frequency bands $(9-12 \mathrm{~Hz}$; for similar methods, see Canolty et al., 2006; Itthipuripat et al., 2013a). Next, the single-trial alpha and theta data were sorted into different experimental conditions (just like the ERPs). Maximal time-domain SDs of the Gaussian wavelet filters were computed separately for alpha and theta (i.e., alpha: $\mathrm{SD}=208 \mathrm{~ms}$; theta: $\mathrm{SD}=468 \mathrm{~ms}$ ). Alpha and theta data were then baseline-corrected across a time window extending $200 \mathrm{~ms}$ before their respective time-domain SD (i.e., alpha data were baseline-corrected from 408 to $208 \mathrm{~ms}$ before target onset and theta data were baseline-corrected from 668 to $468 \mathrm{~ms}$ before target onset).

We then examined the impact of expectation type, flicker rate, and the expectation status of target on two ERP components: the occipital negative-going component recorded from the $\mathrm{Oz}$ electrode and the central parietal positive (CPP) component recorded from the central posterior $(\mathrm{CPz})$ electrode. We used three-way repeated-measures ANOVAs with within-subject factors for expectation type (3 levels: color expectation, orientation expectation, and motor expectation), flicker rate (2 levels: fast and slow), and the expectation status of the target (3 levels: expected, neutral, and unexpected) to evaluate the influence of these factors on the amplitude of the ERP components. These ANOVAs were performed on the mean ERP amplitudes across consecutive $50 \mathrm{~ms}$ windows from $250 \mathrm{~ms}$ before to $1500 \mathrm{~ms}$ after target onset for the targetlocked data and from $300 \mathrm{~ms}$ before to $100 \mathrm{~ms}$ after the response onset for the response-locked data. Corrections for multiple comparisons was implemented using the false discovery rate (FDR) method (Benjamini and Hochberg, 1995) based on both target-locked and response-locked data from $\mathrm{CPz}$ and $\mathrm{Oz}$ electrodes. The impact of expectation type, flicker rate, and expectation on the CPP slope was examined on both target- and response-locked data. The CPP slope was measured as the slope of a straight line fitted to the ERP waveform for each subject, using the interval 200 to $550 \mathrm{~ms}$ for the target-aligned CPP and -350 to $0 \mathrm{~ms}$ for the response-aligned CPP (for similar methods, see Kelly and O'Connell, 2013). We then performed $t$ tests to examine the impact of flicker rate and a one-way ANOVA to assess the impact of expectation on the CPP slope. In the case of no significant main effects, follow-up one-tailed $t$ tests and Bayes factor analyses were performed on the signals collapsed across consecutive $50 \mathrm{~ms}$ windows.

The same ANOVA analyses were then performed on the induced parietal alpha amplitude recorded from the Pz electrode and frontal theta amplitude recorded from the FCz electrode. These electrodes were chosen as they displayed maximum response amplitude in the alpha and theta range respectively. ANOVAs were performed on the mean theta amplitudes across consecutive $50 \mathrm{~ms}$ windows from $700 \mathrm{~ms}$ before to $1500 \mathrm{~ms}$ after target onset for the target-locked data and from $300 \mathrm{~ms}$ before to $100 \mathrm{~ms}$ after the response onset for the response-locked data. The same ANOVAs were performed on the mean alpha amplitudes from $450 \mathrm{~ms}$ before to $1500 \mathrm{~ms}$ after target onset for the target-locked data and from $300 \mathrm{~ms}$ before to $100 \mathrm{~ms}$ after the response onset for the responselocked data. In addition, we performed follow-up one-tailed $t$ tests to compare the impact of flicker rates and a one-way ANOVA to assess the impact of expectation on both ERP components as well as theta and alpha amplitude from each individual expectation type (color expectation/ orientation expectation/motor expectation). Note that corrections for multiple comparisons were computed separately for alpha and theta based on its target-locked and response-locked data from the $\mathrm{Pz}$ and FCz electrode respectively. In the case of significant main effects of either flicker rate or expectation, one-tailed follow-up tests were performed on individual expectation type signal amplitudes averaged across significant time windows.

To further examine the impact of expectation, we performed a post hoc Bayes factor $t$ tests (Edwards et al., 1963; Wagenmakers, 2007; Rouder et al., 2009) on VN amplitude, CPP slope, and CPP amplitude during the time windows where the effect of flicker rates was significant. We report Bayes factors expressing the probability of the data given H1 (i.e., there was an expectation effect) relative to $\mathrm{H} 0$ (i.e., there was no expectation effect). Although Bayes factors are not evaluated against a fixed threshold to determine significance, a Bayes factor $>3$ is generally considered to indicate positive evidence in favor of $\mathrm{H} 1$, whereas a value $<0.33$ is generally considered evidence for $\mathrm{H} 0$.

\section{Results}

\section{Behavioral results}

In the present study, participants performed an orientation discrimination task in which feature expectation and motor expectation were independently manipulated on a block-by-block basis (Fig. 1). Targets were red or blue bars coherently oriented at $0^{\circ}$ (horizontal) or $90^{\circ}$ (vertical), and participants indicated the target by pressing the left (L) or right key (R). Each response button was associated with a specific conjunction of color and orientation. Half of the participants were instructed to map the 
left button to red horizontal and blue vertical targets and the right button to blue horizontal and red vertical targets (this mapping was reversed for the other half of the participants). There were four main conditions in the task: neutral (no expectation), color expectation, orientation expectation, and motor expectation. Each target was composed of two features: color and orientation, and the expectation status of the target was manipulated by presenting one type of target more frequently than the other target type within the same target feature. That is, for a given block of trials (e.g., a color expectation block), one target type (e.g., red target) was expected, whereas the other target type (i.e., blue target) was unexpected. The other target feature was orthogonal to this expectation manipulation (i.e., it was equally likely that the target would be vertical or horizontal).

We manipulated the flicker rate of the stimuli to manipulate the amount of sensory information being presented per unit time, with more information about the stimuli available as the flicker rate increased. Consequently, participants should have higher accuracy and faster reaction times on trials where stimuli were rendered at a fast compared with a slow flicker rate. In addition, we also predicted better performance when the target feature or its corresponding motor response was expected.

As shown in Figure 1, there was a significant main effect of the flicker rate manipulation on behavioral performance such that participants were faster and more accurate on trials where stimuli were presented at a fast $(50 \mathrm{~Hz})$ compared with slow $(33.33 \mathrm{~Hz})$ flicker rate $\left(\mathrm{RT}: F_{(1,16)}=152.73, p<0.001\right.$, accuracy: $F_{(1,16)}=$ $12.69, p=0.003)$. This effect of flicker rate on behavior confirms that our manipulation successfully impacted the amount of sensory evidence available on each trial. Also, shown in Figure 1 was a significant main effect of expectation on both RT and accuracy (expected/neutral/unexpected, RT: $F_{(2,16)}=97.51, p<0.001$; accuracy: $\left.F_{(2,16)}=77.26, p<0.001\right)$. Post hoc $t$ tests revealed that participants were faster in the expected compared with the neutral $\left(t_{(16)}=8.21, p<0.001\right)$ and unexpected conditions $\left(t_{(16)}=\right.$ $12.60, p<0.001)$. Similarly, accuracy was higher in the expected compared with the neutral $\left(t_{(16)}=5.81, p<0.001\right)$ and unexpected conditions $\left(t_{(16)}=10.09, p<0.001\right)$. Participants were also faster $\left(t_{(16)}=6.64, p<0.001\right)$ and more accurate in the neutral compared with the unexpected conditions $\left(t_{(16)}=8.18\right.$, $p<0.001)$. However, there was no significant interaction between expectation and flicker rate on either RT or accuracy (expected/neutral/unexpected vs fast/slow flicker, RT: $F_{(2,16)}=0.59$, $p=0.56$; accuracy: $\left.F_{(2,16)}=1.36, p=0.27\right)$. Finally, there was no main effect of expectation type on RT or accuracy (expectation about color/orientation/motor response, RT: $F_{(2,16)}=1.01, p=$ 0.38 ; accuracy: $\left.F_{(2,16)}=0.64, p=0.54\right)$, and there was no interaction between expectation type and flicker rate (color expectation/orientation expectation/motor expectation versus fast/slow flicker rate, RT: $F_{(2,16) \max }=1.20, p_{\min }=0.32$; accuracy: $F_{(2,16) \max }=$ $0.34, p_{\min }=0.85$ ).

\section{EEG results}

The early visual negative (VN) potential

We used an early visual negative potential $(\mathrm{VN})$, which peaked $\sim 150$ $300 \mathrm{~ms}$ after target onset at the central occipital electrode $(\mathrm{Oz})$ to index the magnitude of early sensory-evoked visual responses. The amplitude of this early sensory ERP increases as the amount of sensory evidence increases (e.g., visual contrast or motion coherence: Johannes et al., 1995; Wyart et al., 2012a; Itthipuripat et al., 2014b, 2017; Loughnane et al., 2016) and we used $\mathrm{Oz}$ because the visual stimuli were presented at the center of the screen. We predicted that presenting stimuli at a fast, compared with a slow flicker rate, should lead to an increase in the amount of sensory evidence per unit time and thus greater sensory-evoked re- sponses as indexed by an increase in $\mathrm{VN}$ amplitude. According to the sensory enhancement account, expectation about stimulus features or associated motor responses should also increase the $\mathrm{VN}$ amplitude if expectation improves the efficiency of early sensory processing. The classic SDT account, on the other hand, would predict expectation to have no effect on this neural measure of early sensory processing.

\section{Fast flicker rate increases VN amplitude}

We analyzed differences in both target-locked and response-locked VN amplitude in sliding $50 \mathrm{~ms}$ windows and corrected for multiple comparisons using FDR method based on both target-locked and responselocked data from $\mathrm{CPz}$ and $\mathrm{Oz}$ electrodes (see Materials and Methods). We found that $\mathrm{VN}$ amplitude was significantly larger on fast compared with slow flicker rate trials from 200 to $300 \mathrm{~ms}$ after target onset $\left(F_{(1,16)}=\right.$ $10.43-20.20 ; p=0.0004-0.0052$, FDR-corrected threshold $=0.0059$; see Fig. $2 A$, left). This flicker rate effect was consistent across expectation type $\left(t_{(16)}=-3.98,-4.65,-4.89\right.$ with all $p$ values $<0.001$ for color expectation, orientation expectation, and motor expectation, respectively; Fig. $2 A$, right).

\section{Expectation does not affect VN amplitude}

In contrast, expectation had little impact on the $\mathrm{VN}$, with only 1 of 35 time windows showing a trend toward significance that occurred outside the peak window of the $\mathrm{VN}$ and did not survive FDR correction $\left(F_{(2,16) \max }=4.45, p_{\min }=0.02\right.$, FDR-corrected threshold $=0.0059$; Fig. $2 B)$. Note also that during this time window, $\mathrm{VN}$ amplitude was marginally higher on unexpected compared with expected trials. This marginal effect is in the opposite direction from that predicted by the sensory enhancement account. A post hoc analysis of the Bayes factor indicated either slightly positive or equivocal evidence in favor of the hypothesis that expectation had no effect on $\mathrm{VN}$ amplitude $\left(\mathrm{BF}_{10}=0.33-1.35\right.$ across all comparisons; Table 1).

We then examined the interaction between flicker rate and expectation on the amplitude of the $\mathrm{VN}$ and found that although one time window showed a trend toward an increased VN amplitude on fast-flickered expected trials, none survived correction for multiple-comparison $\left(F_{\max }=\right.$ $4.66, p_{\min }=0.02$, only one time window had a $p$ value $<0.05$, FDRcorrected threshold $<0.001)$.

\section{Excluding the first 20 trials following a change in expectation type} does not influence the null effects of expectation on the VN

We next examined whether these null effects of expectation on the VN could be caused by a failure of participants to build an expectation until the end of each experimental block. To evaluate this account, we first examined the time course of expectation effects on behavioral accuracy and RT. We found that expectation had a relatively fast impact on RT and accuracy early in each block (Fig. 1C). Specifically, after excluding the first 20 trials following a change in expectation types, we found significant effects of flicker rate and expectation on RT (flicker rate: $F_{(1,16)}=$ $125.29, p<0.001$; expectation: $\left.F_{(2,16)}=118.29, p<0.001\right)$ and accuracy (flicker rate: $F_{(1,16)}=11.19, p=0.0004$; expectation: $F_{(2,16)}=77.22, p<$ $0.001)$ across expectation type.

Moreover, we replicated our main findings with respect to $\mathrm{VN}$ amplitude after discarding the first 20 trials from each experimental block (Fig. 3). VN amplitude was greater on fast compared with slow flicker rate trials from 200 to $300 \mathrm{~ms}$ after target onset $\left(F_{(1,16)}=4.99-11.01 ; p=\right.$ $0.004-0.04$, FDR-corrected threshold $=0.0043$; Fig. $3 A$, left $)$. This effect was consistent across expectation type $\left(t_{(16)}=-3.76,-4.84,-6.52\right.$ with all $p$ values $<0.001$ for color expectation, orientation expectation, and motor expectation, respectively; Fig. $3 A$, right). In contrast, manipulations of expected target features did not impact the VN amplitude $\left(F_{(2,16) \max }=3.36, p_{\min }=0.05\right.$, FDR-corrected threshold $=0.0043$; Fig. $3 B)$. A post hoc analysis of the Bayes factor indicates either slightly positive or equivocal evidence in favor of the hypothesis that expectation had no effect on $\mathrm{VN}$ amplitude $\left(\mathrm{BF}_{10}=0.25-0.48\right.$ across all comparisons). Finally, we examined an interaction effect between flicker rate and expectation on CPP amplitude and found that no time window survived correction for multiple comparisons $\left(F_{\max }=5.92, p_{\min }=0.007\right.$, FDR-corrected threshold $<0.001$ ). Together, these results demonstrate that even though the $\mathrm{VN}$ is a sensitive marker of the amount of sensory 
A
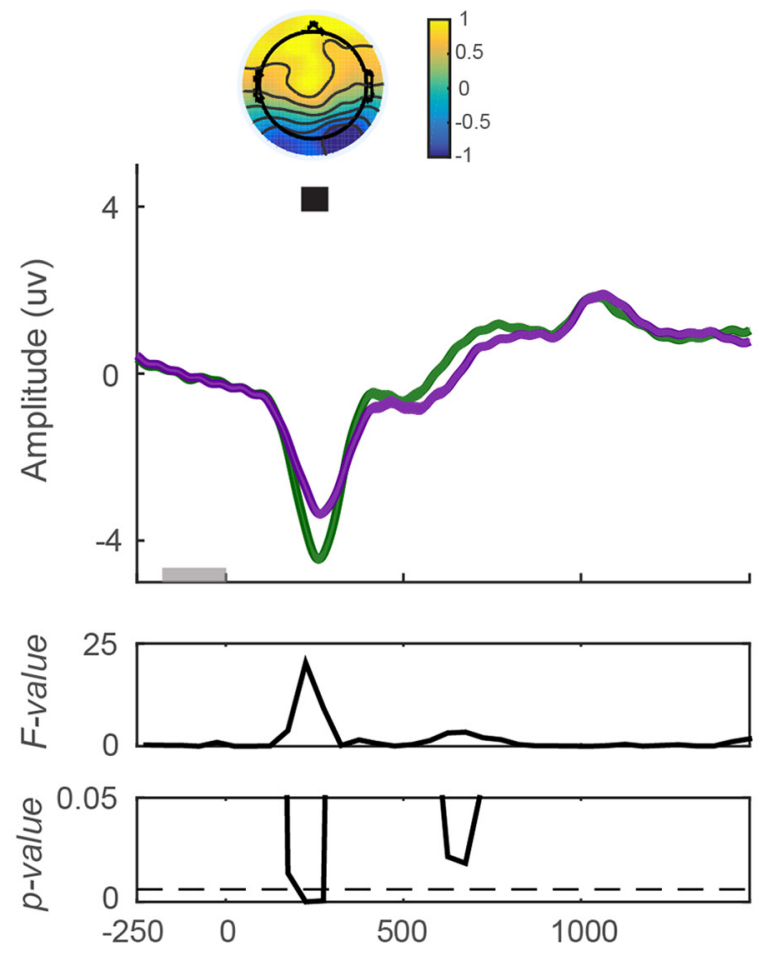

B
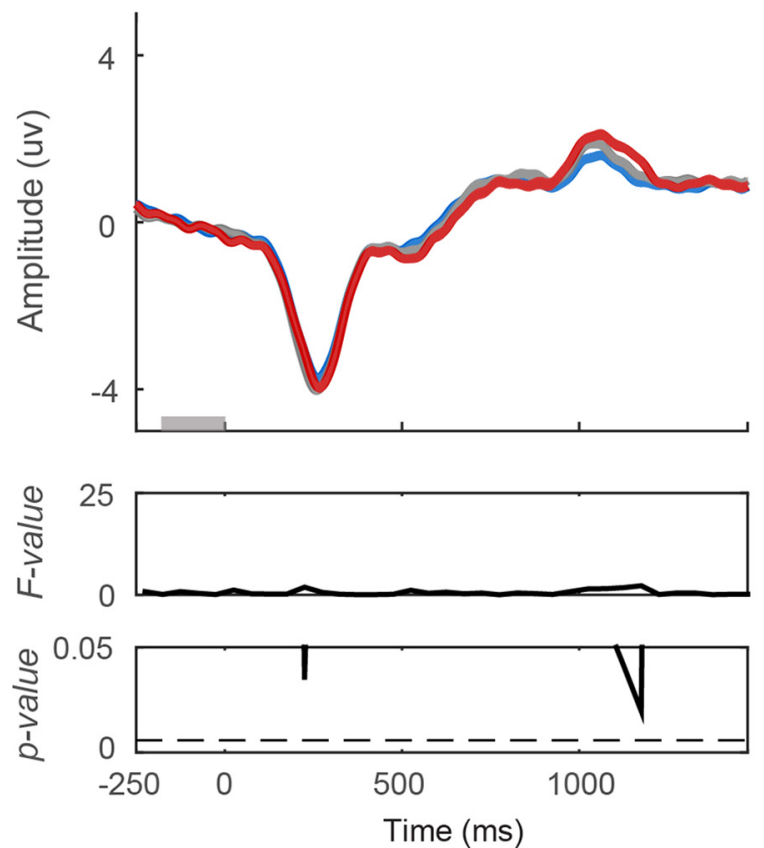

Color Expectation

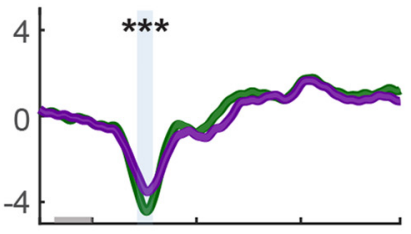

Orientation Expectation

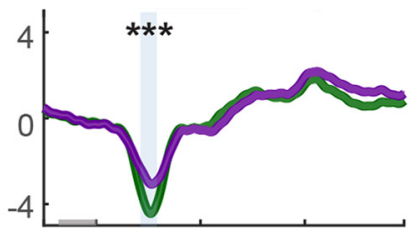

Motor Expectation

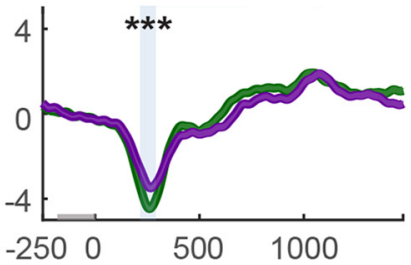

Fast Flicker

Slow Flicker

\section{Color Expectation}

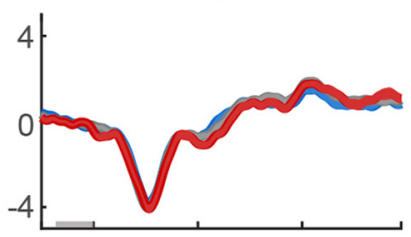

Orientation Expectation

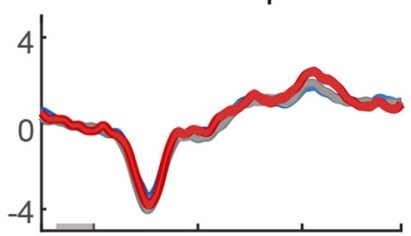

Motor Expectation

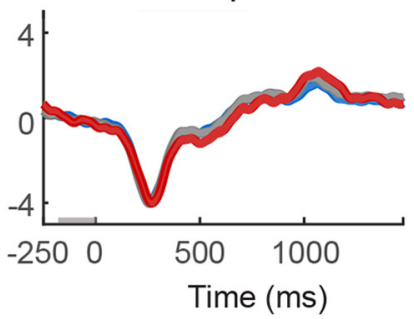

Expected

Neutral

Unexpected

Figure 2. Expectation does not affect early VN amplitude. VN amplitude was computed on data from all trials of each block. $A$, VN plotted from $250 \mathrm{~ms}$ before target onset to $1500 \mathrm{~ms}$ after target onset. VN plotted as a function of flicker rate (fast/slow) and (B) as a function of the expectation status of the target (expected/neutral/unexpected). Left, VN collapsed across expectation type (color/orientation/motor). Right, VN from individual expectation type. Fast flicker rate induced a significantly more negative VN from 200 to $300 \mathrm{~ms}$ after target onset. Significant main effect of flicker rate, ${ }^{* * *} p<0.001$. 
Table 1. Bayes factor analyses of flicker rate and expectation status of the target

\begin{tabular}{|c|c|c|c|c|}
\hline \multirow[b]{2}{*}{ Neural measures } & \multicolumn{2}{|l|}{ Flicker rate comparison } & \multicolumn{2}{|l|}{ Expectation comparisons } \\
\hline & Fast vs slow flicker rate & Expected vs unexpected & Expected vs neutral & Neutral vs unexpected \\
\hline $\begin{array}{l}\text { VN amp, tg-locked, } \\
200 \text { to } 300 \mathrm{~ms} \\
\text { CPP slope }\end{array}$ & $\begin{array}{l}t=-5.51, p<0.001, \mathrm{BF}_{10}=545.62 \\
t=3.52, p=0.003, \mathrm{BF}_{10}=15.34\end{array}$ & $\begin{array}{l}t=0.91, p=0.38, \mathrm{BF}_{10}=0.36 \\
t=0.48, p=0.64, \mathrm{BF}_{10}=0.28\end{array}$ & $\begin{array}{l}t=2.06, p=0.06, \mathrm{BF}_{10}=1.35 \\
t=-1.64, p=0.12, \mathrm{BF}_{10}=0.76\end{array}$ & $\begin{array}{l}t=-0.81, p=0.43, \mathrm{BF}_{10}=0.33 \\
t=1.85, p=0.08, \mathrm{BF}_{10}=1.01\end{array}$ \\
\hline $\begin{array}{l}\text { CPP amp, tg-locked, } \\
200 \text { to } 750 \text { ms } \\
\text { CPP amp, resp-locked, }\end{array}$ & $t=7.36, p<0.001, \mathrm{BF}_{10}=11,528$ & $t=-0.93, p=0.37, \mathrm{BF}_{10}=0.36$ & $t=-0.001, p=1.00, \mathrm{BF}_{10}=0.25$ & $t=-0.64, p=0.53, \mathrm{BF}_{10}=0.30$ \\
\hline $\begin{array}{l}-300 \text { to }-200 \mathrm{~ms} \\
-100 \text { to } 0 \mathrm{~ms}\end{array}$ & $\begin{array}{l}t=3.75, p=0.002, \mathrm{BF}_{10}=23.55 \\
t=3.45, p=0.003, \mathrm{BF}_{10}=13.69\end{array}$ & $\begin{array}{l}t=-1.10, p=0.29, \mathrm{BF}_{10}=0.42 \\
t=0.18, p=0.86, \mathrm{BF}_{10}=0.25\end{array}$ & $\begin{aligned} t & =-0.47, p=0.65, \mathrm{BF}_{10}=0.27 \\
t & =-0.60, p=0.56, \mathrm{BF}_{10}=0.29\end{aligned}$ & $\begin{array}{l}t=-0.53, p=0.60, \mathrm{BF}_{10}=0.28 \\
t=0.81, p=0.43, \mathrm{BF}_{10}=0.33\end{array}$ \\
\hline
\end{tabular}

evidence available in the display, manipulating expectations about target features or motor responses has a negligible impact on its magnitude.

\section{The centro-parietal positive potential (CPP)}

The CPP recorded from the $\mathrm{CPz}$ electrode is an established ERP marker thought to track a running sum of sensory evidence over time (Squires et al., 1973, 1975a,b; O'Connell et al., 2012; Kelly and O'Connell, 2013; Itthipuripat et al., 2015; Loughnane et al., 2016; Twomey et al., 2015). Thus, we predicted an increase in CPP amplitude and slope before its peak when stimuli were rendered at a fast flicker rate. The sensory enhancement account would also predict this pattern of results when the feature of the target or its associated motor response is expected. On the other hand, the classic SDT account would not predict any expectationrelated modulations of either the amplitude or slope of the pre-peak CPP.

\section{Fast flicker rate increases the pre-peak amplitude and decreases} the post-peak amplitude of the CPP

We found a significant increase in CPP amplitude on trials where stimuli were rendered at a fast compared with slow flicker rate (Fig. $4 A$, left). The increases in the amplitude of the CPP were most pronounced from 200 to $750 \mathrm{~ms}$ after target onset $\left(F_{(1,16)}=10.43-47.74 ; p=0-0.0052\right.$, FDRcorrected threshold $=0.0059)$; and from 300 to $200 \mathrm{~ms}$ and from 100 to $0 \mathrm{~ms}$ before response onset $\left(F_{(1,16)}=13.21-13.36 ; p=0.0021-0.0022\right.$, FDR-corrected threshold $=0.0059 ; F_{(1,16)}=10.08-12.36 ; p=0.0029$ 0.0059, FDR-corrected threshold $=0.0059$, respectively; Fig. $4 A$, left). Post hoc $t$ tests revealed that the effects of flicker rate on CPP amplitude were consistent across expectation type (from 200 to $750 \mathrm{~ms}$ after target onset: $t_{(16)}=5.49,4.27,6.98$ with all $p<0.001$ for color expectation, orientation expectation, and motor expectation, respectively; from 300 to $200 \mathrm{~ms}$ before response onset: $t_{(16)}=2.36,1.04,5.55$ with $p=0.02$, 0.16 , and $<0.001$ for color expectation, orientation expectation, and motor expectation, respectively; from 100 to $0 \mathrm{~ms}$ before response onset: $t_{(16)}=2.76,1.56,3.99$ with $p=0.01,0.07$, and $<0.001$ for color expectation, orientation expectation, and motor expectation, respectively; Figure $4 A$, right). In addition, after the peak of the target-locked CPP, there was a significant decrease in CPP amplitude from 1050 to $1100 \mathrm{~ms}$ after target onset $\left(F_{(1,16)}=11.57 ; p=0.004\right.$, FDR-corrected threshold $=$ 0.0059), suggesting that decision-making associated with the faster flicker rate target required less processing time as evidenced by the earlier offset of the post-peak CPP amplitude. Post hoc $t$ tests revealed that the flicker rate effect during this time window was consistent across expectation type $\left(t_{(16)}=-2.78,-2.19,-2.07\right.$ with $p=0.01,0.02,0.03$ for color expectation, orientation expectation, and motor expectation, respectively).

\section{Expectation does not impact the pre-peak amplitude of CPP but violations of expectation modulates the post-peak amplitude of $C P P$}

We next evaluated the impact of expectation on CPP amplitude. We found no effect of expectation on target-locked CPP amplitude before the peak or on response-locked CPP amplitude. A post hoc Bayes factor analysis was generally consistent with these null results $\left(\mathrm{BF}_{10}=0.25-\right.$ 0.42; Table 1). While there was no effect of expectation on target-locked CPP amplitude before the peak amplitude, expectation did have an impact on the amplitude of the CPP after the peak amplitude from 950 to $1200 \mathrm{~ms}$ after target onset $\left(F_{(2,16)}=11.53-17.08 ; p=0-0.0002\right.$, FDR- corrected threshold $=0.0059$; Fig. $4 B$, left). During this interval, the amplitude of the CPP was higher on unexpected compared with neutral $\left(t_{(16)}=-5.17, p<0.001\right)$ and expected trials $\left(t_{(16)}=-5.08, p<0.001\right)$. Follow-up repeated-measures one-way ANOVAs also showed that this expectation effect was consistent across expectation type $\left(F_{(2,16)}=3.65\right.$, $13.77,8.15$ with all $p<0.05$ for color expectation, orientation expectation, and motor expectation, respectively; Fig. $4 B$, right). Finally, we examined the interaction between flicker rate and expectation on the amplitude of CPP and found that no time window survived correction for multiple comparisons (target-locked: $F_{\max }=3.17, p_{\min }=0.06$; response-locked: $F_{\max }=0.78, p_{\min }=0.46$, FDR-corrected threshold $<0.001)$.

Fast flicker rate increases the CPP slope but expectation does not We then more directly examined the rise-time (or slope) of the targetlocked CPP, which was computed over an interval from 200 to $550 \mathrm{~ms}$ after target onset (see Materials and Methods). We found a higher slope when targets were rendered at a fast compared with slow flicker rate (mean slopes $\pm 1 \mathrm{SEM}=0.032 \pm 0.003$ and $0.027 \pm 0.004 \mu \mathrm{V} / \mathrm{ms}$ for fast and slow flicker rate, respectively; $\left.t_{(16)}=3.52, p=0.003\right)$. Post hoc $t$ tests also revealed that the effect of flicker rate on CPP slope was consistent across expectation type $\left(t_{(16)}=2.46,2.82,2.67\right.$ with all $p<0.05$ for color expectation, orientation expectation, and motor expectation respectively). Given this demonstration of the CPP's sensitivity to changes in sensory evidence, we tested whether expectation also impacted the efficiency of early sensory processing in a manner similar to increasing the amount of sensory evidence. However, unlike the flicker rate effect, we found no effect of expectation on the slope of the CPP (mean slopes \pm 1 $\mathrm{SEM}=0.029 \pm 0.004,0.031 \pm 0.004$ and $0.028 \pm 0.004 \mu \mathrm{V} / \mathrm{ms}$ for expected, neutral, and unexpected conditions, respectively; $F_{(2,16)}=$ $1.91, p=0.16)$, and this was true for all manipulations of expectation type $\left(F_{(2,16)}=2.67,1.86,1.75\right.$ with $p=0.08,0.17,0.19$ for color expectation, orientation expectation, and motor expectation, respectively). Further, post hoc Bayes factor analysis indicated either slightly positive or equivocal evidence in favor of the hypothesis that expectation had no effect on CPP slope $\left(\mathrm{BF}_{10}=0.28-1.01\right.$; Table 1$)$.

Excluding the first 20 trials following a change in expectation type does not influence the effects of expectation on the CPP

Discarding the first 20 trials from each block following a change in expectation type did not influence the CPP effects reported above (Fig. 5). The amplitude of pre-peak CPP was greater on fast compared with slow flicker rate trials from 250 to $750 \mathrm{~ms}$ after target onset and from 250 to $200 \mathrm{~ms}$ before response onset (target-locked: $F_{(1,16)}=11.01-33.05 ; p<$ $0.001-0.0043$; response-locked $F_{(1,16)}=11.50 ; p=0037$, FDR-corrected threshold $=0.0043$, respectively; Fig. $5 A$, left). These flicker rate effects were consistent across expectation type (from 250-750 ms after target onset: $t_{(16)}=5.38,2.40,4.68$ with all $p<0.05$ for color expectation, orientation expectation and motor expectation, respectively; from 250 to $200 \mathrm{~ms}$ before response onset: $t_{(16)}=2.11,-0.02,4.77$ with $p=0.03$, 0.51 , and $<0.001$ for color expectation, orientation expectation, and motor expectation, respectively; Figure $5 A$, right). In addition, the postpeak amplitude of the CPP was lower on fast compared with slow flicker rate trials from 1050 to $1100 \mathrm{~ms}$ after target onset $\left(F_{(1,16)}=\right.$ $11.11 ; p=0.004$, FDR-corrected threshold $=0.0043)$. This decrease 
A
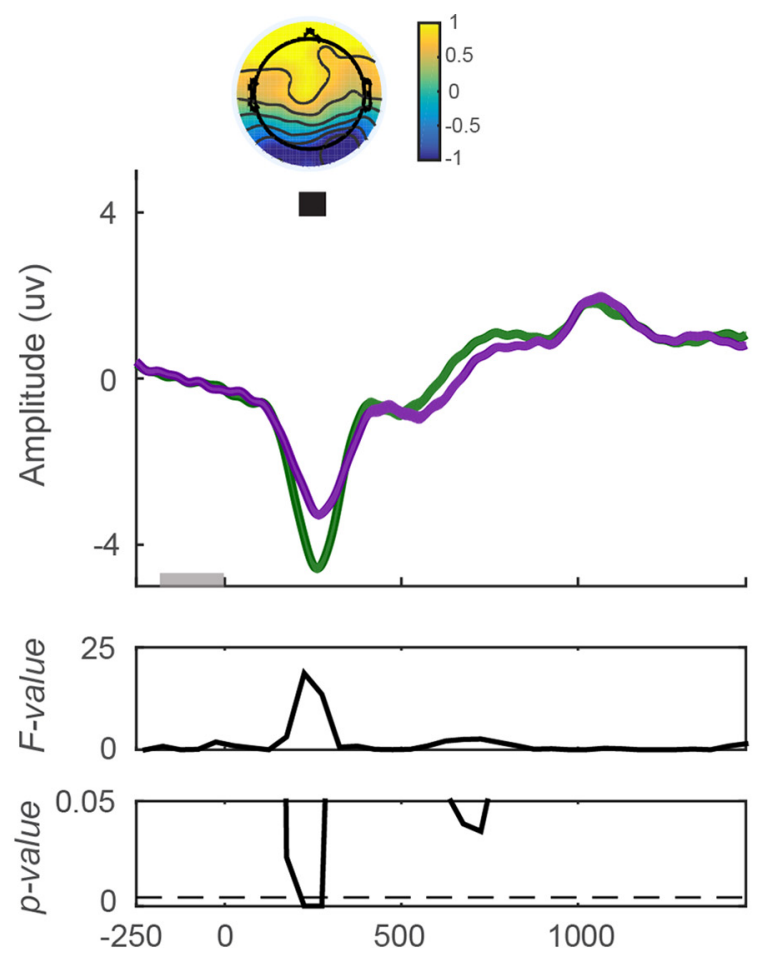

B
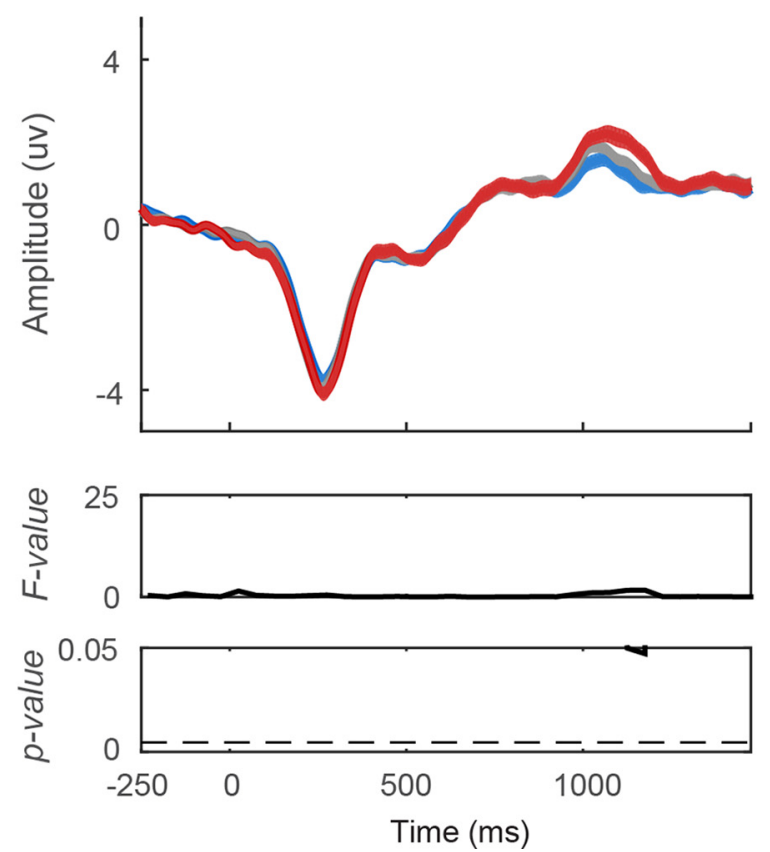

Color Expectation

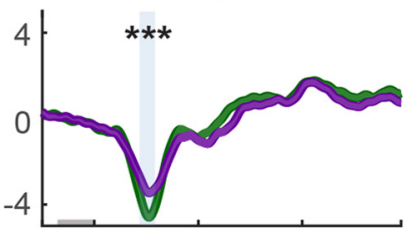

Orientation Expectation

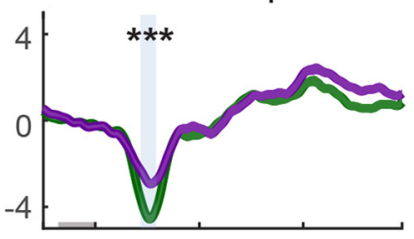

Motor Expectation

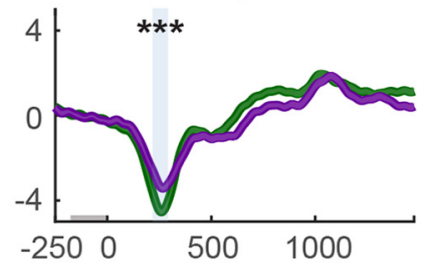

Fast Flicker

Slow Flicker

\section{Color Expectation}
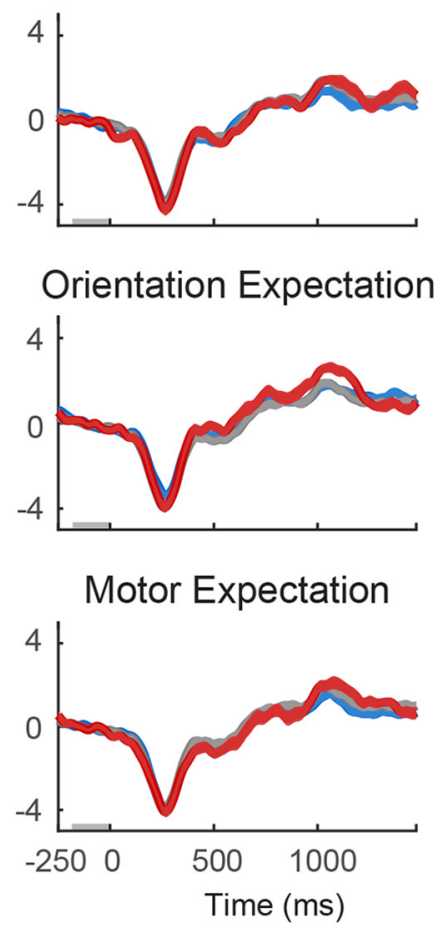

Expected

Neutral

Unexpected

Figure 3. Excluding the first 20 trials following a change in expectation types does not influence the null effect of expectation on the VN. VN amplitude was computed on data after the first 20 trials from each block were discarded. Similar to Figure 2, VN was plotted from $250 \mathrm{~ms}$ before target onset to $1500 \mathrm{~ms}$ after target onset. $A$, VN was plotted as a function of flicker rate (fast/slow) and $(B)$ as a function of expectation status of the target (expected/neutral/unexpected). Left, VN collapsed across expectation type (color/orientation/motor expectation). Right, VN from individual expectation type. Fast flicker rate induced a significantly more negative VN from 200 to $300 \mathrm{~ms}$ after target onset. Significant main effect of flicker rate, ${ }^{* * *} p<0.001$. 
A
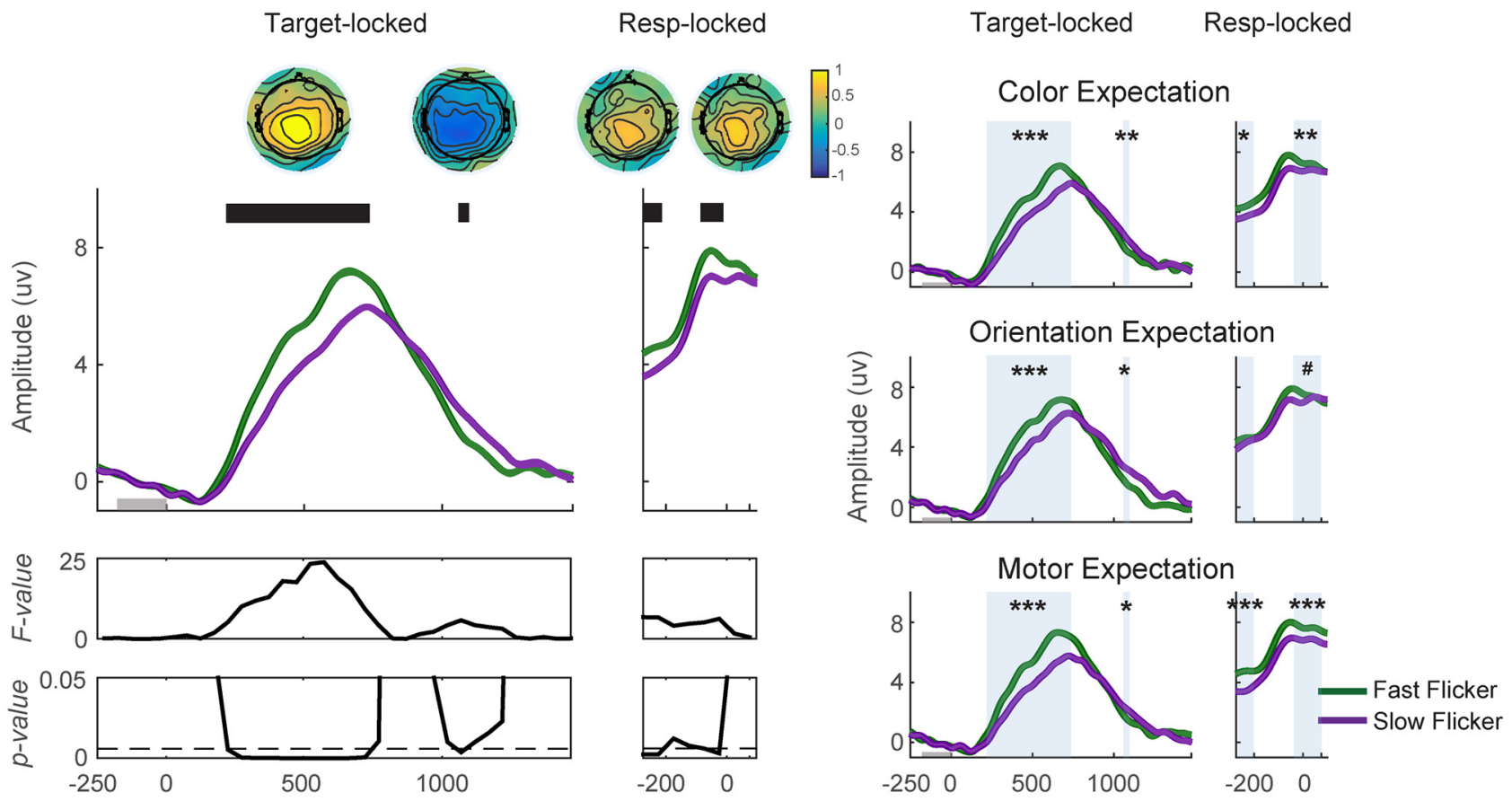

B
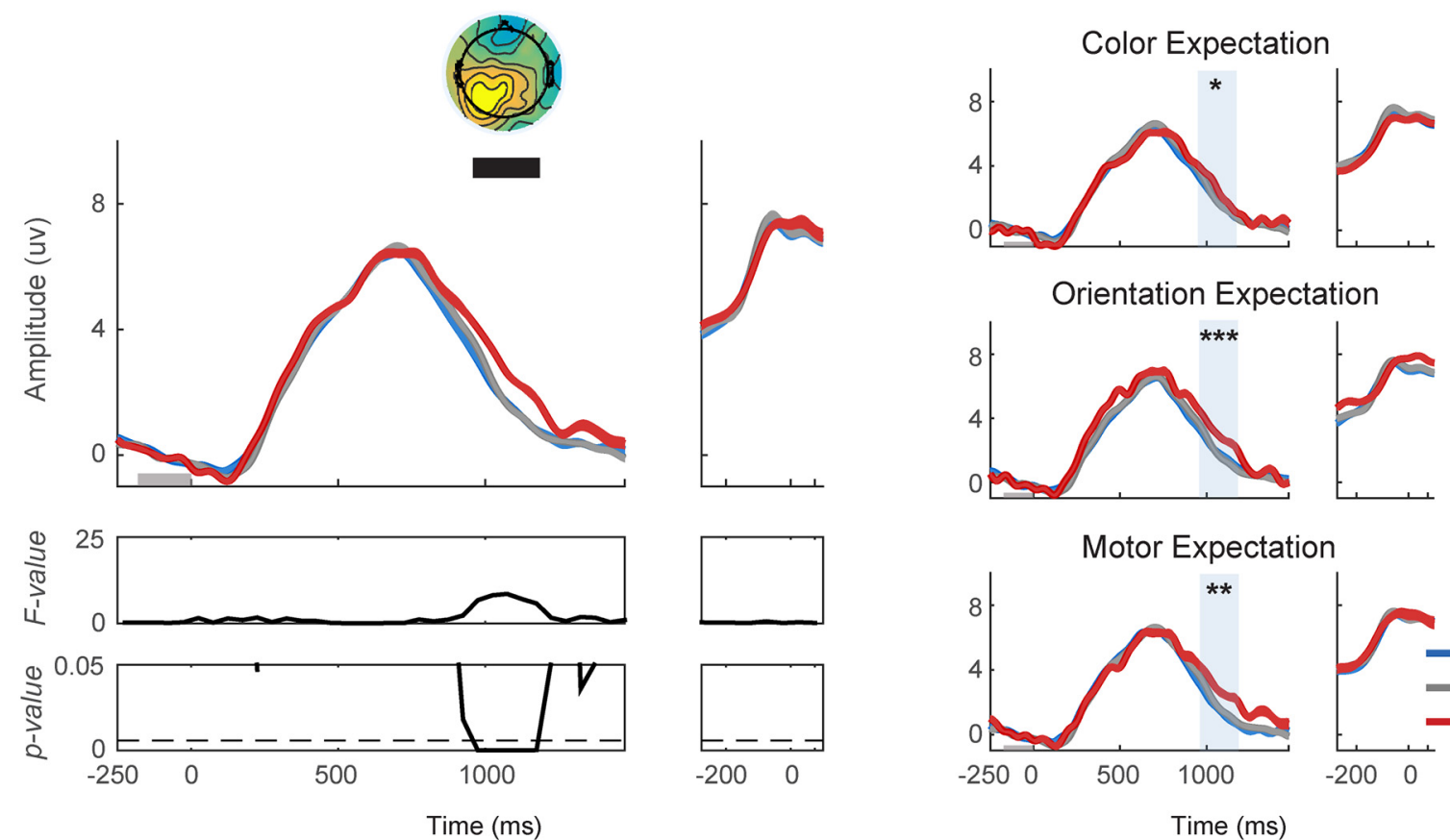

Motor Expectation
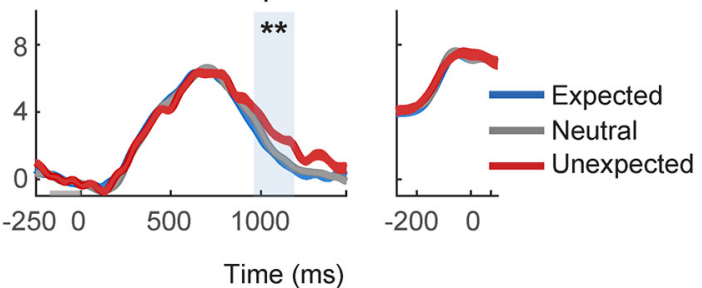

Figure 4. Expectation does not impact the pre-peak CPP amplitude but violations of expectation modulate the post-peak CPP amplitude. CPP amplitude and slope were computed on data from all trials of each block. $A$, Target-locked CPP was plotted from $250 \mathrm{~ms}$ before target onset to $1500 \mathrm{~ms}$ after target onset, whereas response-locked CPP was plotted from $300 \mathrm{~ms}$ before response onset to $100 \mathrm{~ms}$ after the onset. (PP was plotted as a function of flicker rate (fast/slow) and (B) as a function of expectation status of the target (expected/neutral/unexpected). Fast flicker rate induced higher CPP amplitude from 200 to $750 \mathrm{~ms}$ after target onset, and from 300 to 200 and from 100 to 0 ms before response onset. Additionally, after the peak of the target-locked CPP, the CPP amplitude dropped faster on trials where stimuli were presented at the fast flicker rate from 1000 to $1100 \mathrm{~ms}$ after target onset. The effect of expectation on the CPP amplitude emerged from 950 to $1200 \mathrm{~ms}$ after target onset where the CPP amplitude was lower for unexpected compared with neutral and expected trials. Significant main effects of flicker rate and expectation: ${ }^{\#} p<0.1,{ }^{*} p<0.05,{ }^{* *} p<$ 0.01 , and ${ }^{* * *} p<0.001$.

in post-peak CPP amplitude with the fast flicker targets was consistent across expectation type $\left(t_{(16)}=-3.03,-2.24,-1.93\right.$ with $p=$ $0.004,0.02,0.04$ for color expectation, orientation expectation, and motor expectation, respectively).

Similar to the null result obtained when we included all trials, we found no effect of expectation on the pre-peak target-locked CPP ampli- tude or on response-locked CPP amplitude. Post hoc Bayes factor analysis was generally consistent with these null results $\left(\mathrm{BF}_{10}=0.25-0.34\right)$. Instead, expectation had an impact on the post-peak amplitude of the CPP from 950 to $1100 \mathrm{~ms}$ and from 1150 to $1200 \mathrm{~ms}$ after target onset (950$1100 \mathrm{~ms}: F_{(2,16)}=6.97-11.74 ; p=0-0.0002 ; 1150-1200 \mathrm{~ms} ; F_{(2,16)}=$ $11.53-17.08 ; p=0-0.0002 ;$ FDR-corrected threshold $=0.0043$, respec- 
A
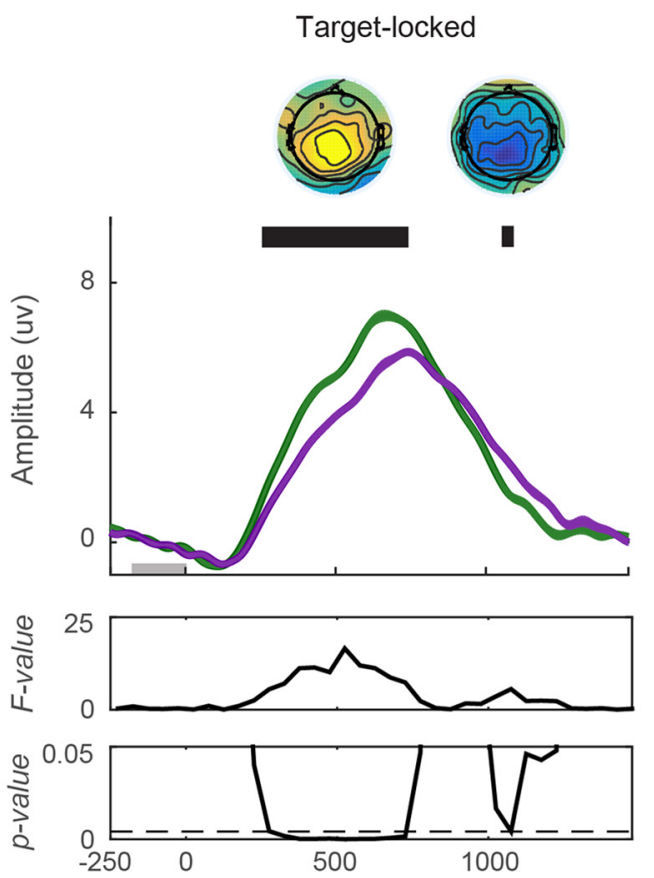

B
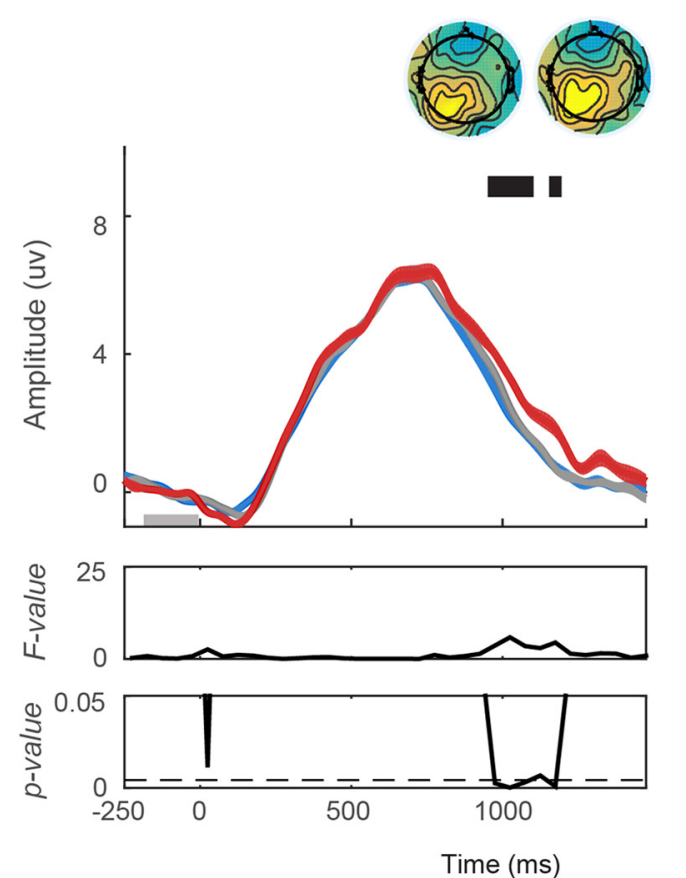

Resp-locked
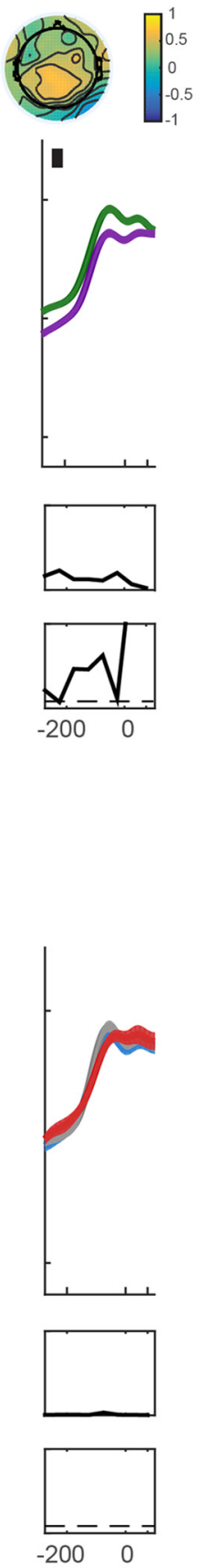

Target-locked Resp-locked

Color Expectation
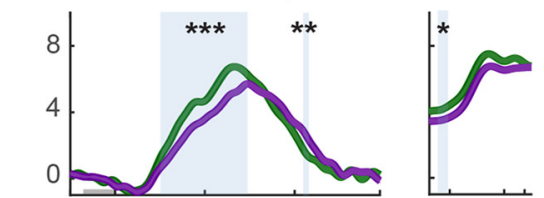

Orientation Expectation
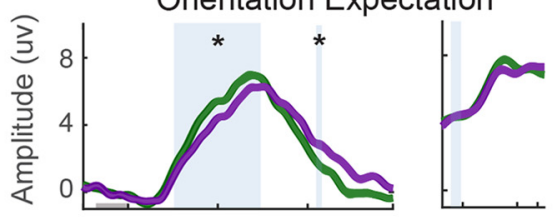

Motor Expectation
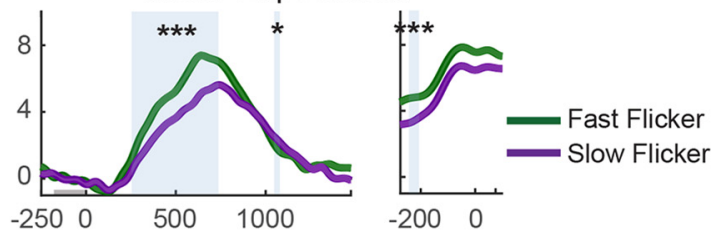

Color Expectation
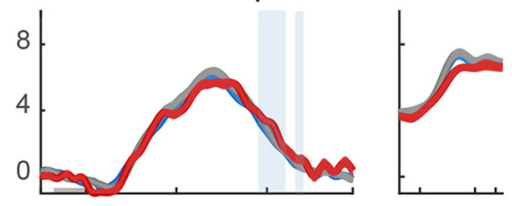

Orientation Expectation

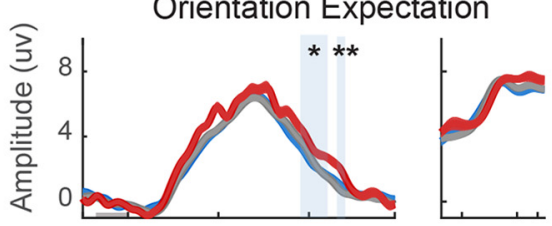

Motor Expectation

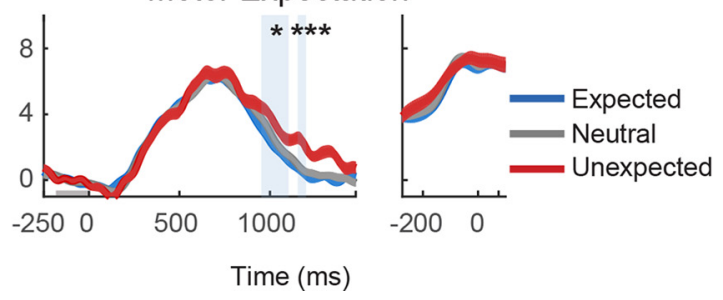

Figure 5. Excluding the first 20 trials following a change in expectation types does not influence the CPP effects. The amplitudes and slopes of the CPP were recomputed after the first 20 trials from each block were discarded. Similar to Figure 4, CPP was plotted from 250 ms before target onset to 1500 ms after target onset, whereas response-locked CPP was plotted from 300 ms before response onset to $100 \mathrm{~ms}$ after response onset. $\boldsymbol{A}$, CPP was plotted as a function of flicker rate (fast/slow) and (B) as a function of the expectation status of the target (expected/neutral/unexpected). The faster flicker rate induced higher CPP amplitude from 250 to $750 \mathrm{~ms}$ after target onset, and from 250 to 200 before response onset. Additionally, after the peak of the target-locked CPP, the CPP amplitude dropped faster on trials where stimuli were presented at a fast flicker rate from 1050 to $1100 \mathrm{~ms}$ after target onset. The effects of expectation on the CPP amplitude emerged from 950 to 1100 ms and from 1150 to $1200 \mathrm{~ms}$ after target onset where the CPP amplitude was lower for unexpected compared with neutral and expected trials. Significant main effects of flicker rate and expectation: ${ }^{*} p<0.1,{ }^{* *} p<0.05,{ }^{* * *} p<0.001$.

tively; Fig. 5B, left). During these intervals, the amplitude of the CPP was higher on unexpected compared with neutral and expected trials (950$1100 \mathrm{~ms}: t_{(16)}=-3.26, p<0.01 ; t_{(16)}=-3.56, p<0.01$, respectively; $1150-1200 \mathrm{~ms}: t_{(16)}=-3.52, p<0.01 ; t_{(16)}=-2.89, p<0.01$, respectively). Further, this expectation effect was consistent across nearly all expectation types $\left(950-1100 \mathrm{~ms}: F_{(2,16)}=2.33,5.19,4.84\right.$ with $p=0.11$,
0.01, 0.01 for color expectation, orientation expectation, and motor expectation, respectively; $1150-1200 \mathrm{~ms}: F_{(2,16)}=0.27,7.66,9.10$ with p's $=0.76,0.002,<0.001$ for color expectation, orientation expectation, and motor expectation, respectively; Fig. $5 B$, right). In addition, we examined the interaction between flicker rate and expectation on the amplitude of the CPP and found that no time window survived correction 
for multiple comparisons (target-locked: $F_{\max }=3.33, p_{\min }=0.05$; response-locked: $F_{\max }=0.29, p_{\min }=0.75$, FDR-corrected threshold $<0.001)$.

Finally, discarding the first 20 trials from each block following a change in expectation types did not influence the effects of flicker rate and expectation on the CPP slope. We found a higher slope when targets were rendered at a fast compared with slow flicker rate (mean slopes \pm 1 $\mathrm{SEM}=0.031 \pm 0.004$ and $0.025 \pm 0.004 \mu \mathrm{V} / \mathrm{ms}$ for fast and slow flicker rates, respectively; $\left.t_{(16)}=4.17, p<0.001\right)$. This flicker rate effect was consistent across expectation types $\left(t_{(16)}=2.97,2.59,2.65\right.$ with all $p<$ 0.05 for color expectation, orientation expectation, and motor expectation, respectively). Similar to what we previously reported when all trials were included, there was no effect of expectation on the slope of the CPP (mean slopes $\pm 1 \mathrm{SEM}=0.027 \pm 0.004,0.029 \pm 0.003$ and $0.028 \pm 0.004$ $\mu \mathrm{V} / \mathrm{ms}$ for expected, neutral, and unexpected conditions, respectively; $\left.F_{(2,16)}=0.33, p=0.72\right)$, and this was true across expectation type $\left(F_{(2,16)}=1.55,2.01,0.02\right.$ with $p=0.23,0.15,0.98$ for color expectation, orientation expectation, and motor expectation, respectively). Further, post hoc Bayes factor analysis indicated slightly positive or equivocal evidence in favor of the hypothesis that expectation had on effect on CPP slope $\left(\mathrm{BF}_{10}=0.26-0.43\right)$, as Bayes factor revealed no substantial evidence in favor of $\mathrm{H} 1$.

Together, the lack of expectation effects on the CPP slope and the significant post-peak expectation-related modulation of CPP amplitude suggest that expectation did not directly impact the efficiency of early sensory processing during perceptual decision-making. Instead, violations of expectation may slow down decision-making by affecting processing after sensory evidence has already been accumulated.

\section{Parietal alpha activity}

The duration of poststimulus reductions in alpha amplitude over parietal cortex has been previously established as an index for alertness and task engagement (von Stein et al., 2000; Fries et al., 2001; Sauseng et al., 2005; Klimesch et al., 2007; Rihs et al., 2007; Hanslmayr et al., 2008; Busch et al., 2009; Kelly et al., 2009; Mathewson et al., 2009; Zhang et al., 2010; Foxe and Snyder, 2011; Bosman et al., 2012). If expectations primarily impact total time on task without modulating early sensory processing, then alpha modulations should build over the course of the trial and track response times.

\section{Flicker rate does not affect parietal alpha activity}

First, we examined the effect of flicker rate on alpha amplitude. We found that a few time windows showed a trend but did not survive correction for multiple comparisons (target-locked: $F_{\max }=9.92, p_{\min }=0.01$, FDRcorrected threshold $=0.002$; response-locked: $F_{\max }=2.62, p_{\min }=0.13$, FDR-corrected threshold $=0.002$; Fig. $6 \mathrm{~A}$, left). Overall, this result suggests that parietal alpha does not reflect the efficiency of early sensory processing.

\section{Violations of expectation induces reductions in parietal alpha amplitude}

We found significant expectation effects on alpha amplitude from 800 to $1150 \mathrm{~ms}$ following target onset $\left(F_{(2,16)}=7.52-10.48 ; p=0.0003-0.002\right.$, FDR-correct threshold $=0.002$; Fig. $6 B$, left). During these time windows, alpha amplitude was significantly lower in the unexpected compared with the expected condition $\left(t_{(16)}=3.42, p=0.002\right)$ and the neutral condition $\left(t_{(16)}=2.71, p=0.008\right)$. Follow-up one-way ANOVAs showed that these expectation effects were consistent across expectation type $\left(F_{(2,16)}=6.57,3.94,9.21\right.$ with $p<0.01,<0.05,<0.001$ for color expectation, orientation expectation, and motor expectation, respectively; Fig. $6 B$, right). Note that the expectation effect on the alpha activity emerged after the CPP peaked. This suggests that the violations of expectation occurred only after early sensory processing had been completed, thus violations of expectation may induce surprise, higher vigilance and more prolonged task engagement (Zimmer et al., 2010; cf. Talsma et al., 2012; Wessel and Aron, 2017).

\section{Frontal theta activity}

Last, we examined the amplitude of frontal theta activity, which has been previously used to index multiple attributes of executive function in the prefrontal cortex, including novelty detection, conflict-monitoring, error detection, response inhibition, and working memory (D'Esposito et al., 1995; Carter et al., 1998; Curtis and Esposito, 2003; Kane and Engle, 2003; Ridderinkhof et al., 2004; Cavanagh et al., 2011, 2012; Itthipuripat et al., 2013b; Aron et al., 2004, 2014, Botvinick et al., 1999, 2001, 2004; Cavanagh and Frank, 2014; Wessel and Aron, 2017). According to the classic SDT account, unexpected targets or motor responses should lead to higher theta amplitude because unexpected events put greater demands on several aspects of executive functions including novelty detection and conflict monitoring. In contrast, the sensory enhancement account would not predict an expectation effect on this neural measure of post-sensory processing.

\section{Fast flicker rate increases frontal theta amplitude}

We found significant increases in frontal theta amplitude on trials with a fast compared with slow flicker rate over a temporal window extending from 400 to $900 \mathrm{~ms}$ after target onset $\left(F_{(1,16)}=10.76-20.95 ; p=0.0003-\right.$ 0.005 , FDR-correct threshold $=0.007$; Fig. $7 \mathrm{~A}$, left). This flicker rate effect was consistent across nearly all expectation conditions $\left(t_{(16)}=\right.$ $1.64,3.60,2.43$ with $p=0.06,<0.01,0.05$ for color expectation, orientation expectation, and motor expectation, respectively; Fig. $7 \mathrm{~A}$, right). This is consistent with the idea that presenting more sensory information per unit time leads to an earlier and stronger engagement of frontal executive control processes.

\section{Violation of expectation increases frontal theta amplitude}

The effect of expectation on frontal theta activity was found from 300-50 ms before response onset $\left(F_{(2,16)}=5.90-7.98 ; p=0.002-0.007\right.$, FDRcorrect threshold $=0.007$; Fig. $7 B$, left). During these time windows, theta amplitude was significantly higher in the unexpected compared with the expected $\left(t_{(16)}=-3.17, p=0.003\right)$ and the neutral condition $\left(t_{(16)}=-1.97, p=0.03\right)$. Follow-up ANOVAs showed that these expectation effects were consistent across most expectation types $\left(F_{(2,16)}=\right.$ 3.07, 9.71, 3.46 with $p=0.06,<0.001,<0.05$ for color expectation, orientation expectation, and motor expectation, respectively; Fig. $7 B$, right). These results are consistent with the notion that violations of expectation engaged the frontal executive control network, which in turn led to the slowing of motor responses.

\section{Discussion}

Expectations about likely sensory features and motor responses can modulate the speed and accuracy of decision-making. According to classic accounts, expectation about a motor response should reduce the amount of evidence needed to trigger a decision (i.e., introduce a response bias; Wald and Wolfowitz, 1949; Green and Swets, 1966; Ratcliff, 1978; Voss et al., 2004; Macmillan and Creelman, 2005; Bogacz et al., 2006; Ratcliff et al., 2016). However, the impact of expectations about sensory features on decision-making is controversial. Some accounts hold that expectation about low-level sensory features such as color, orientation, and motion direction improves sensory encoding by modulating the quality of sensory responses in early visual cortex (Lee and Mumford, 2003; Spratling, 2008; Kok et al., 2012b, 2014). If modulations of sensory responses in visual cortex impact decision-making, they should do so by increasing the efficiency of sensory processing (Diederich and Busemeyer, 2006; Summerfield and de Lange, 2014; Cheadle et al., 2015; Forstmann et al., 2016). However, previous studies of the effect of expectation on sensory processing often used an explicit cue that provided information about a relevant stimulus feature. However cues about the relevance of an impending target lead to the deployment of selective attention, which is well known to influence early sensory responses (Moran and Desimone, 1985; Hillyard and AnlloVento, 1998; McAdams and Maunsell, 1999; Treue and Martínez Trujillo, 1999; Reynolds et al., 2000; Martínez-Trujillo and Treue, 2002; Cohen and Maunsell, 2009; Störmer et al., 2009; Scolari et al., 2012; Anderson et al., 2013; Itthipuripat et al., 2014a,b, 2017; 
A
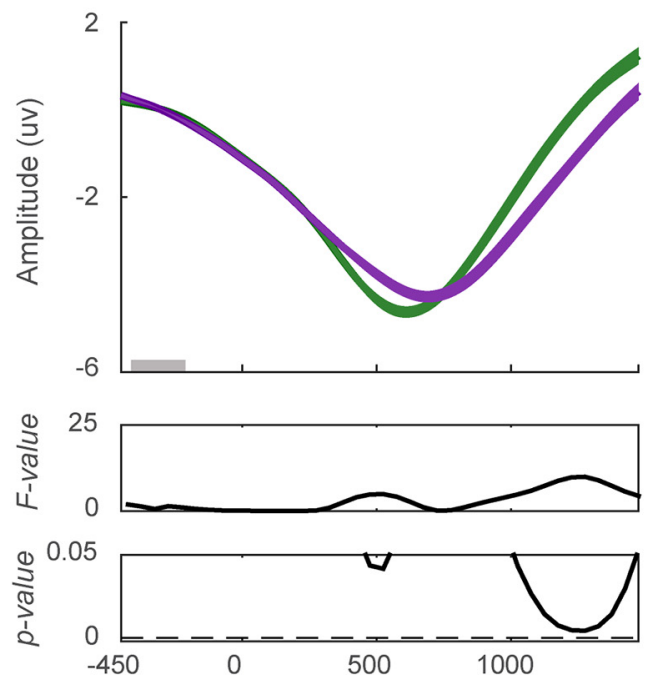

B
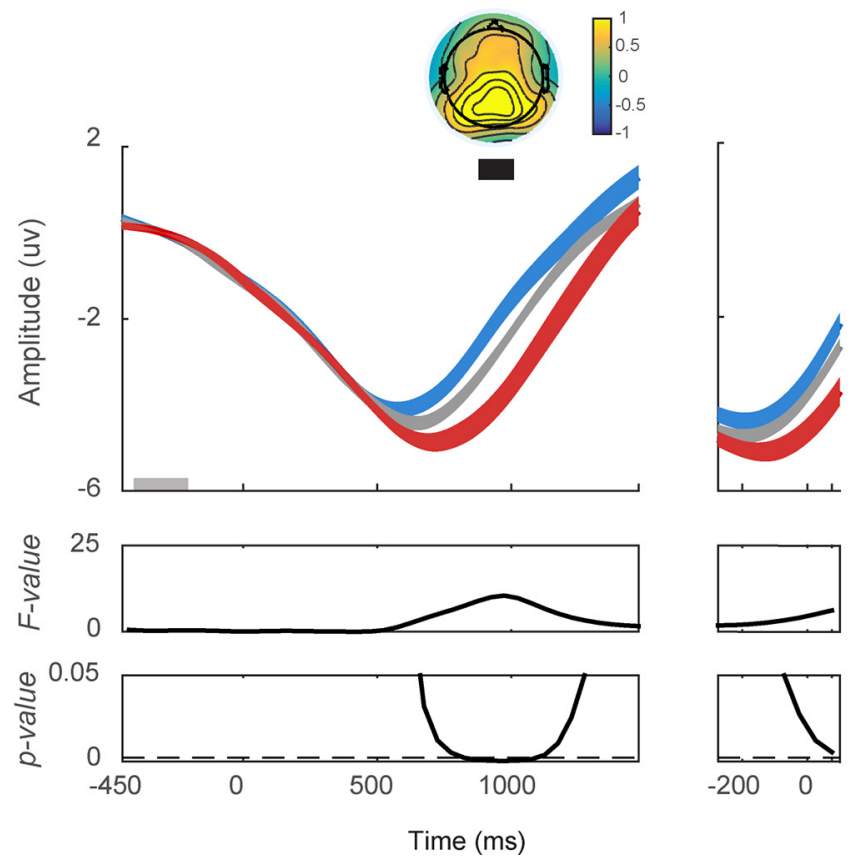

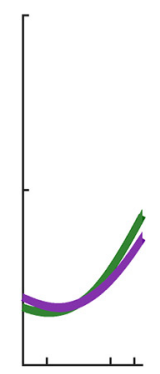

Resp-locked

Target-locked Resp-locked
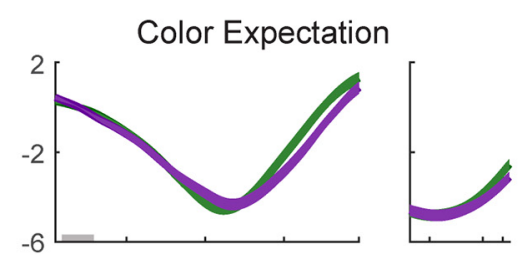

Orientation Expectation
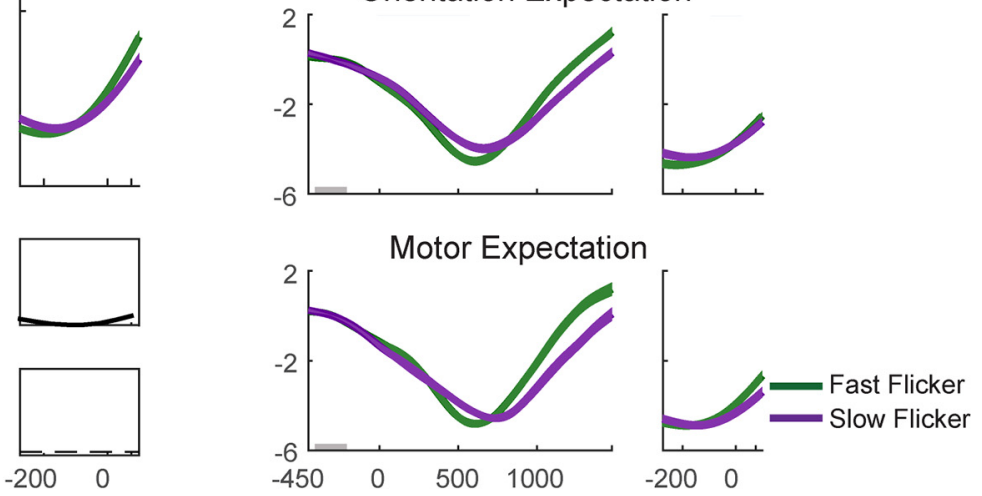
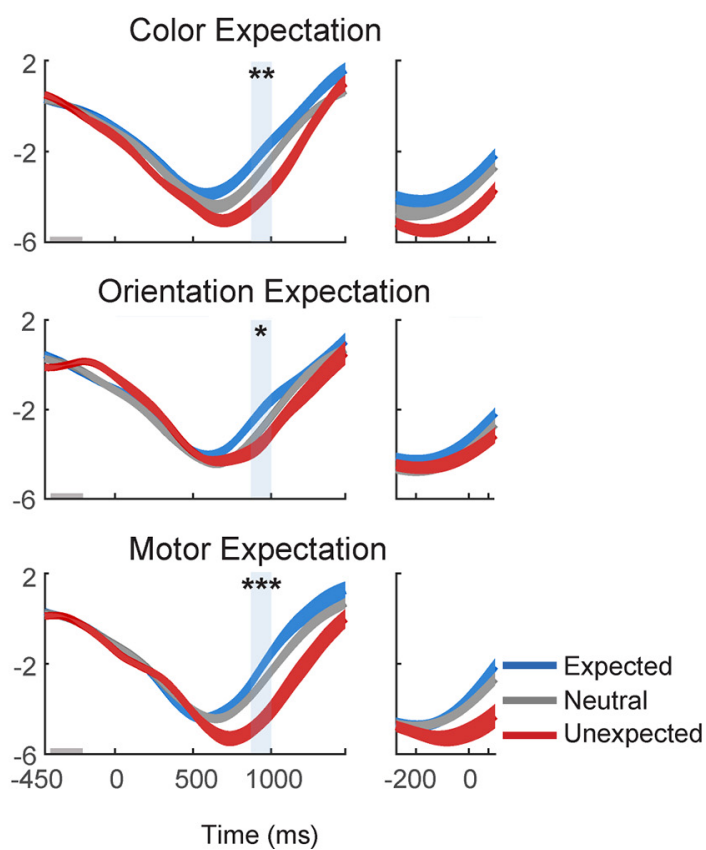

Figure 6. Violations of expectation induce reductions in parietal alpha amplitude. $\boldsymbol{A}$, Target-locked alpha was plotted from $450 \mathrm{~ms}$ before target onset to $1500 \mathrm{~ms}$ after target onset, whereas response-locked alpha was plotted from $300 \mathrm{~ms}$ before response onset to $100 \mathrm{~ms}$ after the onset. The parietal alpha amplitude was plotted as a function of flicker rate (fast/slow; $\boldsymbol{B}$ ) as a function of the expectation status of the target (expected/neutral/unexpected). Expectation had an effect on parietal alpha amplitude from 800 to $1150 \mathrm{~ms}$ after target onset such that alpha amplitude was higher on expected trials during this period. Significant main effects of flicker rate and expectation: ${ }^{*} p<0.05,{ }^{* *} p<0.01$, and ${ }^{* * *} p<0.001$.

Saproo and Serences, 2014; Störmer and Alvarez, 2014). As an alternative to this sensory enhancement account, violations of expectation might influence behavior by interfering with later stages of response selection and response execution, thus leading to slower overall responses.

Here we tested these accounts by orthogonally manipulating expected and relevant feature (e.g., expectation was about target color, but target was defined by orientation). In addition, we also independently manipulated amount of available sensory evi- dence and motor expectation. We found that increasing the amount of sensory evidence led to faster and more accurate responses, as did manipulations of expectation with a comparable magnitude. Moreover, manipulations of sensory evidence increased the amplitude of the VN and the amplitude and slope of the CPP. However, feature and motor expectation had no impact on either of these components. This suggests that even though expectation impact behavior, it does not directly modulate early sensory processing. Note that although interpreting null ef- 
A
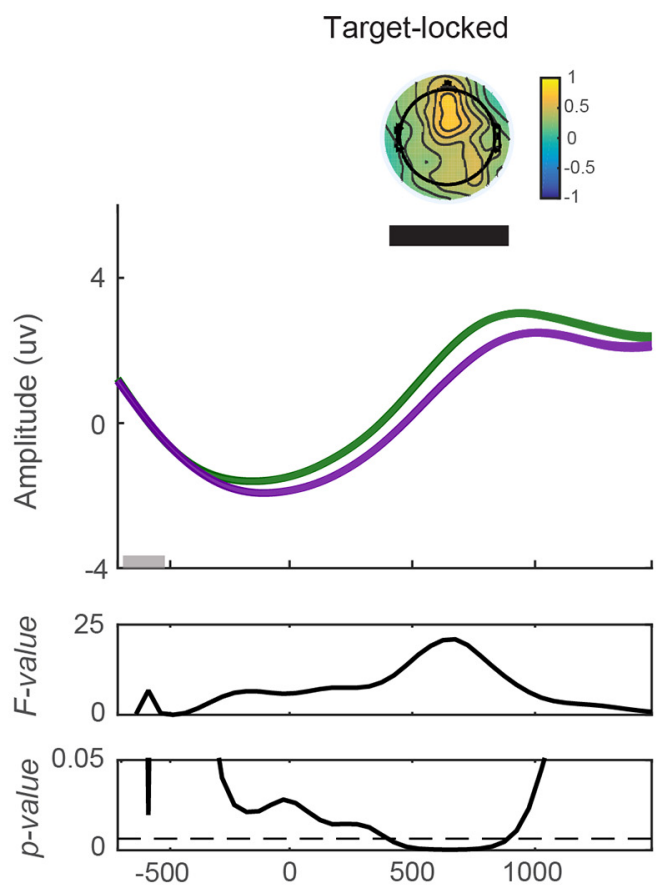

B
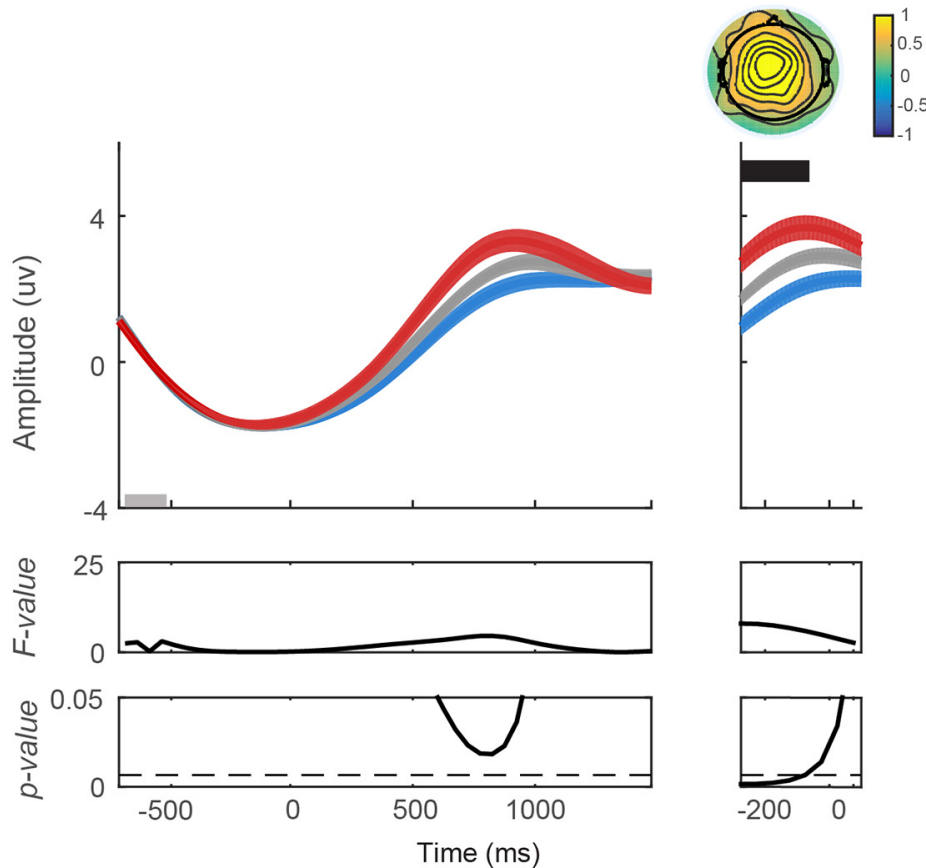

Resp-locked
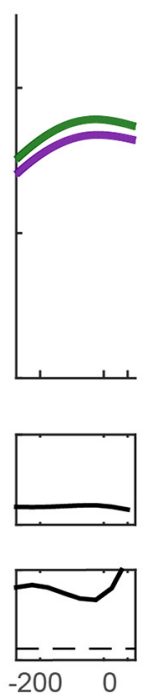

Target-locked Resp-locked

\section{Color Expectation}

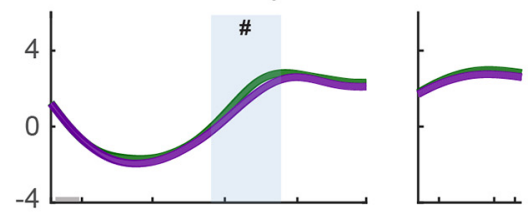

Orientation Expectation

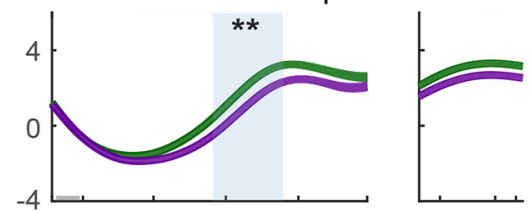

Motor Expectation

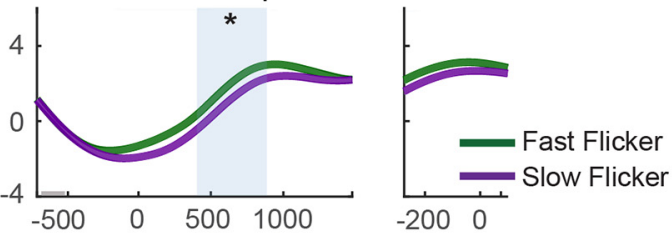

\section{Color Expectation}

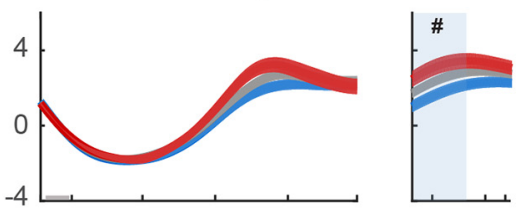

Orientation Expectation

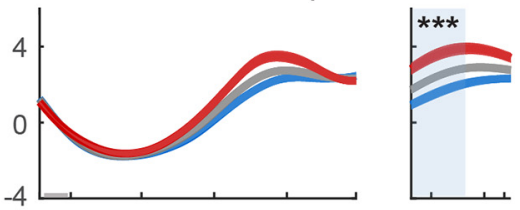

Motor Expectation

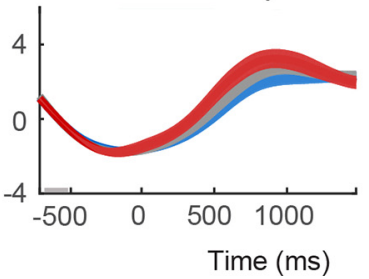

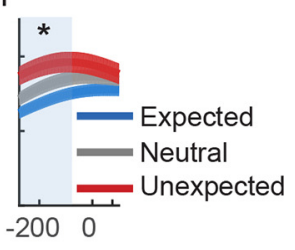

Figure 7. Violations of expectation increase frontal theta amplitude. $\boldsymbol{A}$, Target-locked theta was plotted from 700 ms before target onset to $1500 \mathrm{~ms}$ after target onset, whereas response-locked theta was plotted from $300 \mathrm{~ms}$ before response onset to $100 \mathrm{~ms}$ after the onset. The frontal theta amplitude was plotted as a function of flicker rate (fast/slow; $\boldsymbol{B}$ ) as a function of the expectation status of the target (expected/neutral/unexpected). The theta amplitude was higher on trials where stimuli were rendered at the fast flicker rate from 400 to $900 \mathrm{~ms}$ after target onset. In addition, theta amplitude was higher on unexpected trials from 300 to 50 ms before response onset. Significant main effects of flicker rate and expectation: ${ }^{\#} p<0.1,{ }^{*} p<0.05,{ }^{* *} p<0.01$, and ${ }^{* * *} p<$ 0.001 .

fects is often difficult, the lack of expectation effects on the VN and the CPP cannot be easily explained as a simple lack of sensitivity. We reported comparable effects of flicker rate and expectation on RT and accuracy, yet only found an impact of flicker rate on the VN and the CPP. Furthermore, we found no interaction effects between these two factors on performance or on ERP components.
Note that we did not assess participant's awareness of the expectation manipulation at the end of each block as we wanted to keep the block-by-block manipulation implicit throughout the experiment. We also did not ask participants to report their awareness after the very last block because each participant performed two sessions of the task and we felt that a single response about which feature occurred more frequently in the last block of 
Session 2 would not be a robust indication of their overall perception of the experimental manipulation. That said, if the participants were aware of the expectation manipulation, our observed null effects of expectation on VN and CPP would be even more compelling.

The lack of expectation-related modulations of early sensory responses in our dataset stands in contrast to other recent reports. Using fMRI, one previous study reported that expectation about the orientation of an imperative stimulus improved the quality of stimulus representations in human primary visual cortex (V1; Kok et al., 2012a). However, the design of that study did not clearly disentangle expectations about selective attention to relevant sensory features (the auditory cue used to convey information about expectation also indicated the relevant stimulus feature i.e., an oriented stimulus rendered at 45 or $135^{\circ}$ ). Note that this was not the case in the present study, because expectation was always built on one feature (e.g., color) without providing additional information about overall target relevance since the target feature (i.e., orientation) was equally likely across expected and unexpected trials. In addition, fMRI lacks the time resolution necessary to establish whether early modulations in V1 influence behavior. Related experiments also provide behavioral evidence that expectation may selectively enhance sensitivity to low-level stimulus features (Wyart et al., 2012a; Cheadle et al., 2015). Although consistent with a sensory enhancement account, it is notoriously difficult to use behavioral evidence alone to distinguish between early sensory processing and a reweighting, or selective readout, of sensory information during decisionmaking (Palmer et al., 1993; Shimozaki et al., 2012; cf. Eckstein et al., 2002, 2013, Law and Gold, 2008, 2009).

Finally, complementing the present report, another recent study also provides evidence that expectations do not impact early sensory signals but instead affect later cognitive processes by shifting decision criteria (Bang and Rahnev, 2017). This study manipulated expectations by using pre-cues, post-cues and a reverse correlation method to examine the effects of expectation on a perceptual decision process. Their results demonstrate that both pre- and post-cueing expectations about the stimuli affected decision criteria but not early sensory processing. In line with this finding, Mulder et al., 2012 manipulated the prior probability of a specific direction of motion and used fMRI to examine the effect of expectation on decision-making. Although expectation improved performance, modeling of the behavioral data combined with fMRI data suggest that this effect was likely due to a shift in the starting point of sensory accumulation processes rather than a change in the drift rate (i.e., rate of sensory evidence accumulation). Given the lack of temporal resolution in fMRI, the present EEG data provide complementary and more direct evidence that manipulations of expectation do not affect early sensory processing during decisionmaking.

Although expectation did not impact the amplitude of the VN or the slope or peak-amplitude of the CPP, expectation did lead to a decrease in CPP amplitude after the peak amplitude. In addition, expectation influenced the pattern of alpha/theta oscillatory signals previously used to index task effort and cognitive control. Parietal alpha power showed a sustained decrease on trials in which targets were presented on unexpected features or when unexpected motor responses were required. This is consistent with the notion that violations of expectation require more and prolonged task engagement (Zimmer et al., 2010; Talsma et al., 2012; Wessel and Aron, 2017). Further, we found an increase in frontal theta ampli- tude when the target appeared on unexpected features and when an unexpected motor response was required. This pattern is consistent with the hypothesis that unexpected stimuli require greater executive control during later stages of decision-making and response planning and execution (Cavanagh et al., 2012; Cavanagh and Frank, 2014). For instance, frontal theta, which is thought to be generated from medial frontal cortex, has been implicated in novelty detection and the resolution of response conflict that can cause motor slowing (Botvinick et al., 2001, 2004; Wessel et al., 2012; Cohen and Donner, 2013; Zavala et al., 2014; Voytek et al., 2015; Wessel and Aron, 2017). In sum, our findings suggest that expectations about low-level sensory features, even when the expectations do not provide information about the behavioral relevance of sensory stimuli, primarily impact later decisionand response-related processing. These findings are in line with earlier reports that unexpected stimuli and motor responses lead to global cognitive interruption and motor suppression (Alvarez et al., 2007; Eckstein, 2011; Wessel et al., 2016; Wessel and Aron, 2013, 2017). This suggests that violations of expectation about sensory features influence global networks that modulate late-stage processes including choice evaluation, conflict resolution, and/or motor execution. In the context of the present design, this interpretation is consistent with the fact that participants do not know whether stimuli being presented are "expected" or "unexpected" until they have already integrated sufficient evidence (i.e., the temporal sensory accumulation has reached the associated decision threshold). This situation mirrors real world decision-making in the sense that the importance of learned regularities in the environment, independent of additional information about their behavioral relevance, is not known until a target of visual search is detected. That said, beyond the broad distinctions between relatively early sensory processing and later decisionrelated processing, the present EEG measures do not reveal the specific neural mechanisms that are impacted by violations of expectation. In addition, the optimal means of using prior expectations during decision-making likely depend on the structure of the task as well as overall difficulty levels (Mulder et al., 2012). Finally, given the well documented effects of selective attention to relevant features on early visual processing, simultaneously and orthogonally manipulating both attention and prior expectations during the same task is a critical future direction.

\section{References}

Alvarez GA, Konkle T, Oliva A (2007) Searching in dynamic displays: effects of configural predictability and spatiotemporal continuity. J Vis 7:1-12. CrossRef Medline

Anderson EB, Mitchell JF, Reynolds JH (2013) Attention-dependent reductions in burstiness and action-potential height in macaque area V4. Nat Neurosci 16:1125-1131. CrossRef Medline

Aron AR, Robbins TW, Poldrack RA (2004) Inhibition and the right inferior frontal cortex. Trends Cogn Sci 8:170-177. CrossRef Medline

Aron AR, Robbins TW, Poldrack RA (2014) Inhibition and the right inferior frontal cortex: one decade on. Trends Cogn Sci 18:177-185. CrossRef Medline

Bang JW, Rahnev D (2017) Stimulus expectation alters decision criterion but not sensory signal in perceptual decision making. Scientific Reports 7:17072. CrossRef Medline

Benjamini Y, Hochberg Y (1995) Controlling the false discovery rate: a practical and powerful approach to multiple testing. J R Stat Soc B 57: 289-300.

Berti S, Schröger E (2004) Distraction effects in vision: behavioral and 
event-related potential indices. Neuroreport 15:665-669. CrossRef Medline

Bogacz R, Brown E, Moehlis J, Holmes P, Cohen JD (2006) The physics of optimal decision making: a formal analysis of models of performance in two-alternative forced-choice tasks. Psychol Rev 113:700-765. CrossRef Medline

Bosman CA, Schoffelen JM, Brunet N, Oostenveld R, Bastos AM, Womelsdorf T, Rubehn B, Stieglitz T, De Weerd P, Fries P (2012) Attentional stimulus selection through selective synchronization between monkey visual areas. Neuron 75:875-888. CrossRef Medline

Botvinick MM, Braver TS, Barch DM, Carter CS, Cohen JD (2001) Conflict monitoring and cognitive control. Psychol Rev 108:624-652. CrossRef Medline

Botvinick MM, Cohen JD, Carter CS (2004) Conflict monitoring and anterior cingulate cortex: an update. Trends Cogn Sci 8:539-546. CrossRef Medline

Botvinick M, Nystrom LE, Fissell K, Carter CS, Cohen JD (1999) Conflict monitoring versus selection-for-action in anterior cingulate cortex. Nature 402:179-181. CrossRef Medline

Brainard DH (1997) The psychophysics toolbox. Spat Vis 10:433-436. CrossRef Medline

Busch NA, Dubois J, VanRullen R (2009) The phase of ongoing EEG oscillations predicts visual perception. J Neurosci 29:7869-7876. CrossRef Medline

Canolty RT, Edwards E, Dalal SS, Soltani M, Nagarajan SS, Kirsch HE, Berger MS, Barbaro NM, Knight RT (2006) High gamma power is phaselocked to theta oscillations in human neocortex. Science 313:1626-1628. CrossRef Medline

Carter CS, Braver TS, Barch DM, Botvinick MM, Noll D, Cohen JD (1998) Anterior cingulate cortex, error detection, and the online monitoring of performance. Science 280:747-749. CrossRef Medline

Cavanagh JF, Frank MJ (2014) Frontal theta as a mechanism for cognitive control. Trends Cogn Sci 18:414-421. CrossRef Medline

Cavanagh JF, Wiecki TV, Cohen MX, Figueroa CM, Samanta J, Sherman SJ, Frank MJ (2011) Subthalamic nucleus stimulation reverses mediofrontal influence over decision threshold. Nat Neurosci 14:1462-1467. CrossRef Medline

Cavanagh JF, Figueroa CM, Cohen MX, Frank MJ (2012) Frontal theta reflects uncertainty and unexpectedness during exploration and exploitation. Cereb Cortex 22:2575-2586. CrossRef Medline

Cavanagh JF, Zambrano-Vazquez L, Allen JJ (2012) Theta lingua franca: a common mid-frontal substrate for action monitoring processes. Psychophysiology 49:220-238. CrossRef Medline

Cheadle S, Egner T, Wyart V, Wu C, Summerfield C (2015) Feature expectation heightens visual sensitivity during fine orientation discrimination. J Vis 15:14 1-13. CrossRef Medline

Cohen MR, Maunsell JH (2009) Attention improves performance primarily by reducing interneuronal correlations. Nat Neurosci 12:1594-1600. CrossRef Medline

Cohen MX, Donner TH (2013) Midfrontal conflict-related theta-band power reflects neural oscillations that predict behavior. J Neurophysiol 110:2752-2763. CrossRef Medline

Curtis CE, D'Esposito MD (2003) Persistent activity in the prefrontal cortex during working memory. Trends Cogn Sci 7:415-423. CrossRef Medline

Delorme A, Makeig S (2004) EEGLAB: an open source toolbox for analysis of single-trial EEG dynamics including indepedent component analysis. J Neurosci Methods 134:9-21. CrossRef Medline

Desimone R, Duncan J (1995) Neural mechanisms of selective visual attention. Annu Rev Neurosci 18:193-222. CrossRef Medline

D’Esposito M, Detre JA, Alsop DC, Shin RK, Atlas S, Grossman M (1995) The neural basis of the central executive system of working memory. Nature 378:279-281. CrossRef Medline

Diederich A, Busemeyer JR (2006) Modeling the effects of payoff on response bias in a perceptual discrimination task: bound-change, drift-ratechange, or two-stage-processing hypothesis. Percept Psychophys 68:194207. CrossRef Medline

Eckstein MP (2011) Visual search: a retrospective. J Vis 11, 14:1-36. CrossRef

Eckstein MP, Shimozaki SS, Abbey CK (2002) The footprints of visual attention in the Posner cueing paradigm revealed by classification images. J Vis 2:25-45. CrossRef Medline

Eckstein MP, Mack SC, Liston DB, Bogush L, Menzel R, Krauzlis RJ (2013)
Rethinking human visual attention: spatial cueing effects and optimality of decisions by honeybees, monkeys and humans. Vision Res 85:5-19. CrossRef Medline

Edwards W, Lindman H, Savage LJ (1963) Bayesian statistical inference for psychological research. Psychol Rev 70:193-242. CrossRef

Ester EF, Sutterer DW, Serences JT, Awh E (2016) Feature-selective attentional modulations in human frontoparietal cortex. J Neurosci 36:81888199. CrossRef Medline

Forstmann BU, Ratcliff R, Wagenmakers EJ (2016) Sequential sampling models in cognitive neuroscience: advantages, applications, and extensions. Annu Rev Psychol 67:641-666. Medline

Foxe JJ, Snyder AC (2011) The role of alpha-band brain oscillations as a sensory suppression mechanism during selective attention. Front Psychol 2:154. CrossRef Medline

Fries P, Reynolds JH, Rorie AE, Desimone R (2001) Modulation of oscillatory neuronal synchronization by selective visual attention. Science 291: 1560-1563. CrossRef Medline

Green DM, Swets JA (1966) Signal detection theory and psychophysics. New York, NY: Wiley.

Hanslmayr S, Pastötter B, Bäuml KH, Gruber S, Wimber M, Klimesch W (2008) The electrophysiological dynamics of interference during the Stroop task. J Cogn Neurosci 20:215-225. CrossRef Medline

Hickey C, Chelazzi L, Theeuwes J (2010) Reward changes salience in human vision via the anterior cingulate. J Neurosci 30:11096-11103. CrossRef Medline

Hillyard SA, Anllo-Vento L (1998) Event-related brain potentials in the study of visual selective attention. Proc Natl Acad Sci U S A 95:781-787. CrossRef Medline

Itthipuripat S, Cha K, Byers A, Serences JT (2017) Two different mechanisms support selective attention at different phases of training. PLoS Biol 15:e2001724. CrossRef Medline

Itthipuripat S, Cha K, Rangsipat N, Serences JT (2015) Value-based attentional capture influences context dependent decision-making. J Neurophysiol 114:560-569. CrossRef Medline

Itthipuripat S, Serences JT (2016) Integrating levels of analysis in Systems and Cognitive Neurosciences: selective attention as a case study. Neuroscientist 22:225-237. CrossRef Medline

Itthipuripat S, Garcia JO, Serences JT (2013a) Temporal dynamics of divided spatial attention. J Neurophysiol 109:2364-2373. CrossRef Medline

Itthipuripat S, Wessel JR, Aron AR (2013b) Frontal theta is a signature of successful working memory manipulation. Exp Brain Res 224:255-262. CrossRef Medline

Itthipuripat S, Ester EF, Deering S, Serences JT (2014a) Sensory gain outperforms efficient readout mechanisms in predicting attention-related improvements in behavior. J Neurosci 34:13384-13398. CrossRef Medline

Itthipuripat S, Garcia JO, Rungratsameetaweemana N, Sprague TC, Serences JT (2014b) Changing the spatial scope of attention alters patterns of neural gain in human cortex. J Neurosci 34:112-123. CrossRef Medline

Jiang J, Summerfield C, Egner T (2013) Attention sharpens the distinction between expected and unexpected percepts in the visual brain. J Neurosci 33:18438-18447. CrossRef Medline

Johannes S, Münte TF, Heinze HJ, Mangun GR (1995) Luminance and spatial attention effects on early visual processing. Cogn Brain Res Cogn Brain Res 2:189-205. CrossRef Medline

Kane MJ, Engle RW (2003) Working-memory capacity and the control of attention: the contributions of goal neglect, response competition, and task set to stroop interference. J Exp Psychol Gen 132:47-70. CrossRef Medline

Kelly SP, O'Connell RG (2013) Internal and external influences on the rate of sensory evidence accumulation in the human brain. J Neurosci 33: 19434-19441. CrossRef Medline

Kelly SP, Gomez-Ramirez M, Foxe JJ (2009) The strength of anticipatory spatial biasing predicts target discrimination at attended locations: a highdensity EEG study. Eur J Neurosci 30:2224-2234. CrossRef Medline

Klimesch W, Sauseng P, Hanslmayr S (2007) EEG alpha oscillations: the inhibition-timing hypothesis. Brain Res Rev 53:63-88. CrossRef Medline

Kok P, Jehee JF, de Lange FP (2012a) Less is more: expectation sharpens representations in the primary visual cortex. Neuron 75:265-270. CrossRef Medline

Kok P, Rahnev D, Jehee JF, Lau HC, de Lange FP (2012b) Attention reverses 
the effect of prediction in silencing sensory signals. Cereb Cortex 22: 2197-2206. CrossRef Medline

Kok P, Failing MF, de Lange FP (2014) Prior expectations evoke stimulus templates in the primary visual cortex. J Cogn Neurosci 26:1546-1554. CrossRef Medline

Kok P, van Lieshout LL, de Lange FP (2016) Local expectation violations result in global activity gain in primary visual cortex. Sci Rep 6:37706. CrossRef Medline

Law CT, Gold JI (2008) Neural correlates of perceptual learning in a sensory-motor, but not a sensory, cortical area. Nat Neurosci 11:505-513. CrossRef Medline

Law CT, Gold JI (2009) Reinforcement learning can account for associative and perceptual learning on a visual-decision task. Nat Neurosci 12:655663. CrossRef Medline

Lee TS, Mumford D (2003) Hierarchical $\{B\}$ ayesian inference in the visual cortex. J Opt Soc Am A Opt Image Sci Vis 20:1434-1448. CrossRef Medline

Loughnane GM, Newman DP, Bellgrove MA, Lalor EC, Kelly SP, O'Connell RG (2016) Target selection signals influence perceptual decisions by modulating the onset and rate of evidence accumulation. Curr Biol 26: 496-502. CrossRef Medline

Luck SJ (2005) An introduction to event-related potentials and their neural origins. In: An introduction to the event-related potential technique, pp 2-50. Cambridge, MA: MIT.

Macmillan N, Creelman D (2005) Detection theory: a user's guide. New York: Psychology Press.

Makeig S, Bell AJ, Jung TP, Sejnowski TJ (1996) Independent component analysis of electroencephalographic data. NIPS'95 Proceedings of the 8th International Conference on Neural Information Processing Systems, pp $145-151$.

Martínez-Trujillo JC, Treue S (2002) Attentional modulation strength in cortical area MT. Neuron 35:365-370. CrossRef Medline

Martínez-Trujillo JC, Treue S (2004) Feature-based attention increases the selectivity of population responses in primate visual cortex. Curr Biol 14:744-751. CrossRef Medline

Mathewson KE, Gratton G, Fabiani M, Beck DM, Ro T (2009) To see or not to see: prestimulus $\alpha$ phase predicts visual awareness. J Neurosci 29:27252732. CrossRef Medline

Maunsell JH, Treue S (2006) Feature-based attention in visual cortex. Trends Neurosci 29:317-322. CrossRef Medline

McAdams CJ, Maunsell JH (1999) Effects of attention on orientationtuning functions of single neurons in macaque cortical area V4. J Neurosci 19:431-441. CrossRef Medline

Moran J, Desimone R (1985) Selective attention gates visual processing in the extrastriate cortex. Science 229:782-784. CrossRef Medline

Motter BC (1993) Focal attention produces spatially selective processing in visual cortical areas V1, V2, and V4 in the presence of competing stimuli. J Neurophysiol 70:909-919. CrossRef Medline

Mulder MJ, Wagenmakers EJ, Ratcliff R, Boekel W, Forstmann BU (2012) Bias in the brain: a diffusion model analysis of prior probability and potential payoff. J Neurosci 32:2335-2343. CrossRef Medline

O'Connell RG, Dockree PM, Kelly SP (2012) A supramodal accumulationto-bound signal that determines perceptual decisions in humans. Nat Neurosci 15:1729-1735. CrossRef Medline

Palmer J, Ames CT, Lindsey DT (1993) Measuring the effect of attention on simple visual search. J Exp Psychol Hum Percept Perform 19:108-130. Medline

Pelli DG (1985) Uncertainty explains many aspects of visual contrast detection and discrimination. J Opt Soc Am A 2:1508-1532. CrossRef Medline

Ratcliff R (1978) A theory of memory retrieval. Psychol Rev 85:59-108. CrossRef

Ratcliff R, Smith PL, Brown SD, McKoon G (2016) Diffusion decision model: current issues and history. Trends Cogn Sci 20:260-281. CrossRef Medline

Reynolds JH, Chelazzi L (2004) Attentional modulation of visual processing. Annu Rev Neurosci 27:611-647. CrossRef Medline

Reynolds JH, Pasternak T, Desimone R (2000) Attention increases sensitivity of V4 neurons. Neuron 26:703-714. CrossRef Medline

Ridderinkhof KR, Ullsperger M, Crone EA, Nieuwenhuis S (2004) The role of the medial frontal cortex in cognitive control. Science 306:443-447. CrossRef Medline
Rihs TA, Michel CM, Thut G (2007) Mechanisms of selective inhibition in visual spatial attention are indexed by $\alpha$-band EEG synchronization. Eur J Neurosci 25:603-610. CrossRef Medline

Rouder JN, Speckman PL, Sun D, Morey RD, Iverson G (2009) Bayesian $t$ tests for accepting and rejecting the null hypothesis. Psychon Bull Rev 16:225-237. CrossRef Medline

Saproo S, Serences JT (2014) Attention improves transfer of motion information between V1 and MT. J Neurosci 34:3586-3596. CrossRef Medline

Sauseng P, Klimesch W, Stadler W, Schabus M, Doppelmayr M, Hanslmayr S, Gruber WR, Birbaumer N (2005) A shift of visual spatial attention is selectively associated with human EEG alpha activity. Eur J Neurosci 22:2917-2926. CrossRef Medline

Scolari M, Byers A, Serences JT (2012) Optimal deployment of attentional gain during fine discriminations. J Neurosci 32:7723-7733. CrossRef Medline

Scolari M, Edward F, Serences JT (2014) Feature- and object-based attentional modulation in the human visual system. In: The Oxford handbook of attention, pp 573-600. Oxford: Oxford UP.

Serences JT, Kastner, S (2014) A multi-level account of selective attention. In: The Oxford handbook of attention (Kastner S, Nobre K, eds.), pp 76-104. Oxford; New York: Oxford UP.

Shimozaki SS, Schoonveld WA, Eckstein MP (2012) A unified bayesian observer analysis for set size and cueing effects on perceptual decisions and saccades. J Vis 12:27-26. CrossRef Medline

Spratling MW (2008) Predictive coding as a model of biased competition in visual attention. Vision Res 48:1391-1408. CrossRef Medline

Squires KC, Hillyard SA, Lindsay PH (1973) Vertex potentials evoked during auditory signal detection: relation to decision criteria. Percept Psychophys 14:265-272. CrossRef

Squires KC, Squires NK, Hillyard SA (1975a) Decision-related cortical potentials during an auditory signal detection task with cued observation intervals. J Exp Psychol Hum Percept Perform 1:268-279. CrossRef Medline

Squires KC, Squires NK, Hillyard SA (1975b) Vertex-evoked potentials in a rating-scale detection task: relation to signal probability. Behav Biol 13: 21-34. CrossRef Medline

Störmer VS, Alvarez GA (2014) Feature-based attention elicits surround suppression in feature space. Curr Biol 24:1985-1988. CrossRef Medline

Störmer VS, McDonald JJ, Hillyard SA (2009) Cross-modal cueing of attention alters appearance and early cortical processing of visual stimuli. Proc Natl Acad Sci U S A 106:22456-22461. CrossRef Medline

Summerfield C, de Lange FP (2014) Expectation in perceptual decision making: neural and computational mechanisms. Nat Rev Neurosci 15: 745-756. CrossRef Medline

Talsma D, Senkowski D, Soto-Faraco S, Woldorff MG (2012) Influence of top-down attention on multisensory processing. In: Handbook of multisensory processing (Stein BE, Foxe JJ, eds.), Cambridge, MA: MIT.

Treue S, Martínez Trujillo JC (1999) Feature-based attention influences motion processing gain in macaque visual cortex. Nature 399:575-579. CrossRef Medline

Twomey DM, Murphy PR, Kelly SP, O’Connell RG (2015) The classic P300 encodes a build-to-threshold decision variable. Eur J Neurosci 42:16361643. CrossRef Medline

von Stein A, Chiang C, König P (2000) Top-down processing mediated by interareal synchronization. Proc Natl Acad Sci U S A 97:14748-14753. CrossRef Medline

Voss A, Rothermund K, Voss J (2004) Interpreting the parameters of the diffusion model: an empirical validation. Mem Cognit 32:1206-1220. CrossRef Medline

Voytek B, Kayser AS, Badre D, Fegen D, Chang EF, Crone NE, Parvizi J, Knight RT, D'Esposito M (2015) Oscillatory dynamics coordinating human frontal networks in support of goal maintenance. Nat Neurosci 18: 1318-1324. CrossRef Medline

Wagenmakers EJ (2007) A practical solution to the pervasive problems of $p$ values. Psychon Bull Rev 14:779-804. CrossRef Medline

Wald A, Wolfowitz J (1949) Bayes solutions of sequential decision problems. Proc Natl Acad Sci U S A 35:99-102. CrossRef Medline

Wessel JR, Aron AR (2013) Unexpected events induce motor slowing via a brain mechanism for action-stopping with global suppressive effects. J Neurosci 33:18481-18491. CrossRef Medline

Wessel JR, Aron AR (2017) On the globality of motor suppression: 
unexpected events and their influence on behavior and cognition. Neuron 93:259-280. CrossRef Medline

Wessel JR, Danielmeier C, Morton JB, Ullsperger M (2012) Surprise and error: common neuronal architecture for the processing of errors and novelty. J Neurosci 32:7528-7537. CrossRef Medline

Wessel JR, Jenkinson N, Brittain JS, Voets SH, Aziz TZ, Aron AR (2016) Surprise disrupts cognition via a fronto-basal ganglia suppressive mechanism. Nat Commun 7:11195. CrossRef Medline

Wolfe JM (1998) Visual search. Atten Percept Psychophys 20:13-73.

Wyart V, de Gardelle V, Scholl J, Summerfield C (2012a) Rhythmic fluctuations in evidence accumulation during decision making in the human brain. Neuron 76:847-858. CrossRef Medline

Wyart V, Nobre AC, Summerfield C (2012b) Dissociable prior influences of signal probability and relevance on visual contrast sensitivity. Proc Natl Acad Sci U S A 109:3593-3598. CrossRef Medline

Zavala BA, Tan H, Little S, Ashkan K, Hariz M, Foltynie T, Zrinzo L, Zaghloul KA, Brown P (2014) Midline frontal cortex low-frequency activity drives subthalamic nucleus oscillations during conflict. J Neurosci 34: 7322-7333. CrossRef Medline

Zhang J, Meeson A, Welchman AE, Kourtzi Z (2010) Learning alters the tuning of functional magnetic resonance imaging patterns for visual forms. J Neurosci 30:14127-14133. CrossRef Medline

Zimmer U, Itthipanyanan S, Grent-'t-Jong T, Woldorff MG (2010) The electrophysiological time course of the interaction of stimulus conflict and the multisensory spread of attention. Eur J Neurosci 31:1744-1754. CrossRef Medline 